\title{
New methods for the retrieval of chlorophyll red fluorescence from hyperspectral satellite instruments: simulations and application to GOME-2 and SCIAMACHY
}

\author{
Joanna Joiner $^{1}$, Yasuko Yoshida ${ }^{2}$, Luis Guanter ${ }^{3}$, and Elizabeth M. Middleton ${ }^{1}$ \\ ${ }^{1}$ NASA Goddard Space Flight Center, Greenbelt, MD, USA \\ ${ }^{2}$ Science Systems and Applications, Inc., Lanham, MD, USA \\ ${ }^{3}$ Helmholtz Centre, Potsdam, Germany \\ Correspondence to: Joanna Joiner (joanna.joiner@nasa.gov)
}

Received: 8 December 2015 - Published in Atmos. Meas. Tech. Discuss.: 18 January 2016

Revised: 28 June 2016 - Accepted: 11 July 2016 - Published: 23 August 2016

\begin{abstract}
Global satellite measurements of solar-induced fluorescence (SIF) from chlorophyll over land and ocean have proven useful for a number of different applications related to physiology, phenology, and productivity of plants and phytoplankton. Terrestrial chlorophyll fluorescence is emitted throughout the red and far-red spectrum, producing two broad peaks near 683 and $736 \mathrm{~nm}$. From ocean surfaces, phytoplankton fluorescence emissions are entirely from the red region ( $683 \mathrm{~nm}$ peak). Studies using satellite-derived SIF over land have focused almost exclusively on measurements in the far red (wavelengths $>712 \mathrm{~nm}$ ), since those are the most easily obtained with existing instrumentation. Here, we examine new ways to use existing hyperspectral satellite data sets to retrieve red SIF (wavelengths $<712 \mathrm{~nm}$ ) over both land and ocean. Red SIF is thought to provide complementary information to that from the far red for terrestrial vegetation. The satellite instruments that we use were designed to make atmospheric trace-gas measurements and are therefore not optimal for observing SIF; they have coarse spatial resolution and only moderate spectral resolution $(0.5 \mathrm{~nm})$. Nevertheless, these instruments, the Global Ozone Monitoring Instrument 2 (GOME-2) and the SCanning Imaging Absorption spectroMeter for Atmospheric CHartographY (SCIAMACHY), offer a unique opportunity to compare red and far-red terrestrial SIF at regional spatial scales. Terrestrial SIF has been estimated with ground-, aircraft-, or satellitebased instruments by measuring the filling-in of atmospheric and/or solar absorption spectral features by SIF. Our approach makes use of the oxygen $\left(\mathrm{O}_{2}\right) \gamma$ band that is not affected by SIF. The SIF-free $\mathrm{O}_{2} \gamma$ band helps to estimate
\end{abstract}

absorption within the spectrally variable $\mathrm{O}_{2} \mathrm{~B}$ band, which is filled in by red SIF. SIF also fills in the spectrally stable solar Fraunhofer lines (SFLs) at wavelengths both inside and just outside the $\mathrm{O}_{2} \mathrm{~B}$ band, which further helps to estimate red SIF emission. Our approach is then an extension of previous approaches applied to satellite data that utilized only the filling-in of SFLs by red SIF. We conducted retrievals of red SIF using an extensive database of simulated radiances covering a wide range of conditions. Our new algorithm produces good agreement between the simulated truth and retrievals and shows the potential of the $\mathrm{O}_{2}$ bands for noise reduction in red SIF retrievals as compared with approaches that rely solely on SFL filling. Biases seen with existing satellite data, most likely due to instrumental artifacts that vary in time, space, and with instrument, must be addressed in order to obtain reasonable results. Our 8-year record of red SIF observations over land with the GOME-2 allows for the first time reliable global mapping of monthly anomalies. These anomalies are shown to have similar spatiotemporal structure as those in the far red, particularly for drought-prone regions. There is a somewhat larger percentage response in the red as compared with the far red for these areas that are drought sensitive. We also demonstrate that good-quality ocean fluorescence line height retrievals can be achieved with GOME-2, SCIAMACHY, and similar instruments by utilizing the full complement of radiance measurements that span the red SIF emission feature. 


\section{Introduction}

Measurements of chlorophyll fluorescence over both land and ocean are related to photosynthetic function and thus the carbon cycle and climate feedbacks. Observations of solarinduced fluorescence (SIF) from chlorophyll, obtained from specialized satellites, can provide global coverage within a few days at spatial scales relevant to global models $\left(\sim 0.5^{\circ} \times\right.$ $0.5^{\circ}$ grid cells). Satellite instruments that have been utilized to measure chlorophyll SIF over land include the MEdium Resolution Imaging Spectrometer (MERIS) (Guanter et al., 2007), the Japanese Greenhouse gases Observing SATellite (GOSAT) (Joiner et al., 2011, 2012; Frankenberg et al., 2011b; Guanter et al., 2012), the SCanning Imaging Absorption spectroMeter for Atmospheric CHartographY (SCIAMACHY) (Joiner et al., 2012; Köhler et al., 2015; Wolanin et al., 2015; Khosravi et al., 2015), the Global Ozone Monitoring Experiment 2 (GOME-2) (Joiner et al., 2013), and the Orbiting Carbon Observatory 2 (OCO-2) (Frankenberg et al., 2014). Terrestrial SIF in the far-red emission peak derived from these satellites has been used for studies focused on tropical dynamics (Parazoo et al., 2013; Guan et al., 2015a), primary productivity (Guanter et al., 2014; Parazoo et al., 2014; Zhang et al., 2014; Lee et al., 2015; Guan et al., 2015b), the carbon uptake period (Joiner et al., 2014; Walther et al., 2015), and responses to drought (Lee et al., 2013; Yoshida et al., 2015; Sun et al., 2015; Wang et al., 2016). Oceanic SIF measurements have been made with MERIS (Gower and King, 2007), SCIAMACHY and GOME-2 (Wolanin et al., 2015), the MODerate-resolution Imaging Spectroradiometer (MODIS) (Abbott and Letelier, 1999), and the Korean Geostationary Ocean Color Imager (GOCI) (O'Malley et al., 2014). MODIS has been used to detect red tides (e.g., Hu et al., 2005) and to conduct studies related to the physiology, phenology, and productivity of phytoplankton (e.g., Behrenfeld et al., 2009; Morrison and Goodwin, 2010; Gower and King, 2012; McKibben et al., 2012; Westberry et al., 2013; O'Malley et al., 2014; Gower, 2015).

In terrestrial vegetation, chlorophyll fluorescence is emitted at red to far-red wavelengths with two broad peaks near 683 and $736 \mathrm{~nm}$, known as the red and far-red emission features, respectively, as shown in Fig. 1. Oceanic SIF is emitted in the red emission feature. The primary method used to measure the small terrestrial fluorescence signal from passive ground and aircraft remote sensing instrumentation makes use of dark features in spectra of reflected sunlight from oxygen absorption bands in the Earth's atmosphere (see, e.g., Meroni et al., 2009; Rascher et al., 2009, 2015; Damm et al., 2015, and references therein). The stronger $\mathrm{O}_{2}$ A band $(\sim 760 \mathrm{~nm})$ and its somewhat weaker counterpart, the $\mathrm{O}_{2} \mathrm{~B}$ band $(\sim 690 \mathrm{~nm})$, are conveniently located near the peaks of the far-red (but displaced $\sim 20 \mathrm{~nm}$ ) and red $(<5 \mathrm{~nm}$ ) chlorophyll fluorescence emission features, respectively (see Fig. 1).

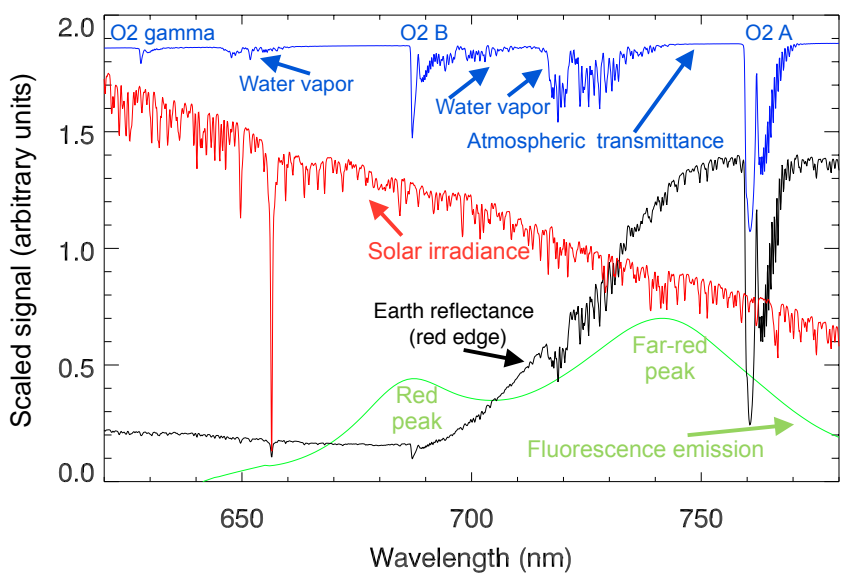

Figure 1. Simulated typical terrestrial spectra (atmospheric transmittance, reflectance, SIF emissions, and solar irradiance as a function of wavelength) computed for an instrument with $\mathrm{FWHM}=0.3 \mathrm{~nm}$.

Solar Fraunhofer lines (SFLs), shown in Fig. 1, have also been used to measure SIF from the ground (e.g., Guanter et al., 2013) and from space (Joiner et al., 2011, 2012; Frankenberg et al., 2011b, 2014; Guanter et al., 2012; Joiner et al., 2013; Köhler et al., 2015; Wolanin et al., 2015; Khosravi et al., 2015). Use of the filling-in of SFLs for satellite retrievals has several advantages as compared with that from oxygen absorption features. Firstly, the spectral structure of SFLs is not modified by clouds, aerosols, surface pressure, surface reflectance, or temperature as is the case with atmospheric oxygen absorption features (e.g., Preusker and Lindstrot, 2009; Joiner et al., 2011; Frankenberg et al., 2011a). Secondly, SIF emissions are partially absorbed in the atmosphere as they travel towards a satellite sensor at wavelengths where oxygen (and water vapor) are radiatively active. Satellite SIF retrieval algorithms that rely mostly or exclusively on the filling-in of SFLs tend to be less complex than those that rely primarily on measurement of the signal in the $\mathrm{O}_{2} \mathrm{~A}$ and $\mathrm{B}$ bands. To effectively utilize these $\mathrm{O}_{2}$ bands, both the downward and upward transmittance through the atmosphere must be accurately estimated. SIF studies to date that rely primarily on these bands have either required an on-ground non-fluorescing target as applied to aircraft- (Rascher et al., 2009) or satellite-based data (Guanter et al., 2007) or retrieve some or all of the parameters affecting the bands, as tested with simulated data (Guanter et al., 2010; Sanders and de Haan, 2013; ESA, 2015; Cogliati et al., 2015) and aircraft observations (Rascher et al., 2015).

Nearly all scientific studies utilizing space-based terrestrial SIF have thus far focused entirely on retrievals from the far-red fluorescence feature. While far-red SIF has been shown to be useful for several applications, having the combination of both red and far-red SIF observations may offer additional information. For example, the relative magnitudes of the red and far-red peaks and their emission intensities are 
sensitive to nitrogen uptake (Corp et al., 2003, 2006, 2010; Campbell et al., 2007, 2008; Zarco-Tejada et al., 2003) and responses to stresses including but not limited to low temperature (Agati et al., 1995, 1996, 2000; Lichtenthaler, 1987, 1988, 1996; Rinderle and Lichtenthaler, 1988; Rossini et al., 2015). Ač et al. (2015) conducted meta-analysis of stress responses to red and far-red passively and actively sensed fluorescence signals for both leaf and canopy measurements. Their results indicate, for example, a higher detectability of water stress in the far red as compared with the red fluorescence, consistent with observations of Daumard et al. (2010), Fournier et al. (2012), Middleton et al. (2015), and references within that showed influences of canopy architecture on far-red fluorescence signals. As noted, red and farred canopy fluorescence measurements may reflect information from different layers of a canopy or leaf (Gitelson et al., 1998; Porcar-Castell et al., 2014) due to higher amounts of reabsorption at red wavelengths. This may lead to higher sensitivity of the far-red signal to deeper layers of the canopy (Verrelst et al., 2015). While most fluorescence is emitted from photosystem II (PSII), a protein complex involved in photosynthesis, Agati et al. (2000) discuss the impact of photosystem I (PSI) and temperature sensitivity on the ratio of far-red to red fluorescence emissions. The PSI contribution grows with wavelength and is considered to be unaffected by biochemistry while the PSII contribution is affected by both physiological regulation as well as leaf structure and chemical composition (Verrelst et al., 2015). In a canopy radiative transport model, Verrelst et al. (2015) then show that the carboxylation capacity $\left(V_{\mathrm{cmo}}\right)$, related to photosynthetic capacity, has its greatest influence in the red emission peak. They further suggest that when trying to relate SIF to photosynthetic quantities such as gross primary productivity (GPP), it would be more beneficial to exploit the full broadband emission flux as compared with a single band in the far red.

SIF emissions must be understood and accounted for in order to make the best possible use oxygen bands for atmospheric applications. For example, the $\mathrm{O}_{2} \mathrm{~A}$ band has been used to estimate cloud pressure (e.g., Kuze and Chance, 1994; Koelemeijer et al., 2001; Kokhanovsky et al., 2003; Loyola et al., 2007) and aerosol plume height (e.g., Sanders et al., 2015). The $\mathrm{O}_{2} \mathrm{~A}$ band has also been used to assess photon pathlength for trace-gas retrievals including $\mathrm{CO}_{2}$ (e.g., O'Dell et al., 2012). It is for this purpose that the Aband spectral region is specifically observed with several atmospheric satellite sensors. Unfortunately for SIF retrieval, some of these instruments, such as GOSAT and OCO-2, include only the $\mathrm{O}_{2}$ A band and not the $\mathrm{B}$ band. However, GOME-2 and SCIAMACHY include both bands.

Terrestrial SIF retrievals near the red peak can have larger errors than those near the far-red peak for several reasons. Firstly, SFLs are not as wide and deep in the red region as those in the far red; this makes the red SFLs less sensitive to filling-in by SIF, particularly at the moderate spectral resolution (full width at half maximum (FWHM) $\sim 0.5 \mathrm{~nm}$ ) of current satellite sensors such as GOME-2 and SCIAMACHY that have spectral coverage in the red region. Secondly, the $\mathrm{O}_{2} \mathrm{~B}$ band covers a fairly large section of the SIF near the peak within the red fluorescence emission feature. Therefore, less spectral range near the red peak is available for the SFL retrieval approach as compared with the far red. Thirdly, the sharp upturn of the red edge in reflectance (see Fig. 1) may complicate retrievals. For example, it may necessitate the use of smaller rather than larger spectral fitting windows for SFL retrievals. Finally, at lower reflectances of the red band as compared with the far red, instrumental artifacts such as dark current and stray light may constitute a larger percentage of the overall observed radiance, leading to larger systematic errors.

Results of simulated red SIF retrievals performed for the TROPOspheric Monitoring Instrument (TROPOMI), a hyperspectral grating instrument to be launched in 2016, show that it should have the capability to retrieve red SIF using relatively small spectral fitting windows (Guanter et al., 2015). Wolanin et al. (2015) showed that a red SIF signal can be detected from SCIAMACHY and GOME-2 over both land and ocean using a spectral fitting window of $681.8-685.5 \mathrm{~nm}$ that is located close to the red SIF emission peak but just outside the $\mathrm{O}_{2} \mathrm{~B}$ band. Results over land for 2 months show spatial patterns similar to those of the Enhanced Vegetation Index (EVI). While promising, the monthly averages show a significant offset between GOME-2 and SCIAMACHY red SIF magnitudes over both land and ocean (Wolanin et al., 2015). Yearly averages of normalized fluorescence line height over ocean from SCIAMACHY appear noisy as compared with those from MODIS. Some of these difficulties in retrieving red SIF should be overcome with the higher spectral resolution instruments designed specifically for fluorescence retrievals $(\leq 0.3 \mathrm{~nm})$ planned with the Fluorescence Explorer (FLEX) mission (Drusch et al., 2016), as recently shown with modeling studies (Cogliati et al., 2015).

Here, we develop new methodology to retrieve terrestrial red SIF using space-based hyperspectral measurements, especially useful for implementation with moderate spectral resolution data currently available. The approaches make use of SFL filling and absorption in and around the $\mathrm{O}_{2} \mathrm{~B}$ (or A) bands. Absorption of sunlight in atmospheric absorption bands is complicated due to photon path modulation by aerosol and cloud profiles, surface pressure, and surface effects such as the bi-directional reflectance distribution function. Our new methodology additionally makes use of the relatively weak $\mathrm{O}_{2} \gamma$-band spectral region, near $627 \mathrm{~nm}$, to estimate the amount of absorption that will be present in the $\mathrm{O}_{2} \mathrm{~B}$ (or A) bands. The $\mathrm{O}_{2} \gamma$ band occurs in a spectral valley between red and blue-green fluorescence features (e.g., Lichtenthaler and Schweiger, 1998) and so has a minimal sensitivity to vegetation's chlorophyll fluorescence. This band also has a minor sensitivity to water vapor absorption as is the case for the $\mathrm{O}_{2} \mathrm{~B}$ band (see Fig. 1). Both bands are affected by clouds and aerosol, in a related and pre- 
dictable way. As will be shown below, principal component analyses (PCAs) of cloudy observations over ocean show that a large fraction of the spectral variability in both bands (>99.96\%) is described by just two modes, one dominated by $\mathrm{O}_{2}$ absorption and the other by $\mathrm{H}_{2} \mathrm{O}$ absorption. Therefore, the fluorescence-free $\mathrm{O}_{2} \gamma$ band can be used to estimate the amount of absorption in the fluorescence-contaminated $\mathrm{O}_{2} \mathrm{~B}$ band under all-sky conditions. Reflectance in between both bands is very similar for cloudy conditions. Over land, there are small differences in reflectance surrounding the two bands that may produce small errors (see, e.g., Fig. 1) when using the $\mathrm{O}_{2} \gamma$ band to estimate B-band absorption. Fluorescence also produces filling-in of SFLs shown in Fig. 1 both inside and outside the $\mathrm{O}_{2} \mathrm{~B}$ band. This provides additional information to disentangle the spectral signature of absorption from fluorescence within $\mathrm{O}_{2} \mathrm{~B}$ band. Use of the $\mathrm{O}_{2} \mathrm{~B}$ band may help to reduce noise in retrievals of the very small red fluorescence signal.

Our methodology is similar to approaches developed for ground- and satellite-based instruments in that radiative transfer in atmospheric absorption bands is approximated using a data-driven PCA approach (Guanter et al., 2012; Joiner et al., 2013; Köhler et al., 2015). Similar PCA methods have also been applied to retrievals of atmospheric trace gases ( $\mathrm{Li}$ et al., 2013, 2015) and have been used to identify different phytoplankton groups with SCIAMACHY (Bracher et al., 2009). While our approach does not require a nearby nonfluorescing target, it does make use of a representative sample of observations over non-fluorescing scenes in order to generate a comprehensive set of fluorescence-free principal components (PCs). For this purpose, we use desert and snowor ice-covered data over land as well as cloudy observations over ocean covering a large range of latitudes and conditions. While our approach is generally applicable to either the $\mathrm{O}_{2} \mathrm{~A}$ - or $\mathrm{B}$-band spectral regions, we focus here on the $\mathrm{B}$ band. The $\mathrm{O}_{2} \mathrm{~A}$ band has more nonlinear absorption (saturated lines) and tends to be brighter than the $\mathrm{O}_{2} \mathrm{~B}$ or $\gamma$ bands over vegetated land (see Fig. 1); this may lead to complex photon path differences for the $\mathrm{O}_{2} \mathrm{~A}$ band as compared with the $\mathrm{B}$ band in the presence of cloud and aerosol. In addition, SIF can be accurately retrieved with existing satellite instrumentation in the far-red emission feature without need of the $\mathrm{O}_{2}$ A band by utilizing the filling-in of SFLs (Joiner et al., 2013).

We conduct simulations to demonstrate the applicability of our approach to current and future satellite instruments. We then apply our technique to data from SCIAMACHY on the European Space Agency (ESA) Environmental Satellite (Envisat) and GOME-2 on the European Meteorological Satellite (EUMETSAT) first operational MetOp-A satellite. The primary function of these instruments was and is to make measurements of atmospheric trace gases. While not optimal for fluorescence retrievals due to their relatively large ground footprints and moderate spectral resolution, their excellent ground sampling, large spectral coverages, and high signal-to-noise ratios (SNRs) enable red SIF retrievals. Nearglobal coverage is provided within a few days from GOME-2 and SCIAMACHY measurements. We also show that these sensors can be used to make high-quality measurements of fluorescence line height over the ocean by utilizing their full spectral content covering the range of red SIF emissions.

\section{GOME-2 and SCIAMACHY satellite data}

We use data from GOME-2, a nadir-viewing cross-track scanning spectrometer that measures radiances at wavelengths from the ultraviolet (UV) to the near-infrared (NIR) (240-790 nm) (Munro et al., 2006). It flies on the series of European Meteorological Satellites (EUMETSAT) as part of the Polar System (EPS) MetOp mission. GOME-2 measures the solar irradiance and backscattered radiance from the Earth in four detector channels. Here, we use revision R2 level 1B data from channel 4 that covers wavelengths 590$790 \mathrm{~nm}$ with a spectral resolution of approximately $0.5 \mathrm{~nm}$ (Callies et al., 2000). The SNR in this channel is fairly high $(>1000)$. The footprint size on the Earth's surface at nadir view is approximately $40 \mathrm{~km} \times 80 \mathrm{~km}$ in its nominal mode with a swath width of $1920 \mathrm{~km}$. In this mode, it takes about 1.5 days for a single GOME-2 instrument to provide coverage of Earth's surface globally.

The first GOME-2 instrument was launched on the MetOp-A satellite 19 October 2006. MetOp satellites are in a polar orbit with an Equator crossing local time near 09:30 LT. The second GOME-2 was launched 17 September 2012 on the MetOp-B platform that has a similar Equator crossing time but is $180^{\circ}$ out of phase with respect to the first flight model. Therefore, one or the other of the GOME2 instruments is making observations of the sunlit part of the Earth. Near-daily global coverage is provided by the two instruments. Since 15 July 2013, GOME-2 onboard MetOp-B makes observations in the nominal mode, while the MetOpA GOME-2 measures in a reduced swath of $960 \mathrm{~km}$ with a nadir pixel size of $\sim 40 \mathrm{~km}$ by $40 \mathrm{~km}$.

SCIAMACHY is a similar grating spectrometer that makes measurements in both limb- and nadir-viewing geometries from UV to NIR wavelengths $(212-2386 \mathrm{~nm})$ in eight separate channels (Lichtenberg, 2006). It was launched in February 2002 on Envisat and took measurements until 8 April 2012 when communication with the host satellite was suddenly lost. Envisat flew in a sun-synchronous orbit with a descending node Equator crossing time near 10:00 LT. Unlike GOME-2, SCIAMACHY typically alternated between limb and nadir observations. Here we use only nadir-mode observations. The nadir observations are therefore not continuous over the course of an orbit but instead show a pattern of blocks of data followed by gaps when the instrument was making limb observations.

In this work, we use SCIAMACHY channel 4, which covers wavelengths between 595 and $812 \mathrm{~nm}$ at a spectral res- 
olution of $0.48 \mathrm{~nm}$. The SCIAMACHY nadir ground footprint size is approximately $30 \mathrm{~km}$ by $60 \mathrm{~km}$ in the along- and across-track directions, respectively, for latitudes between $60^{\circ} \mathrm{N}$ and $60^{\circ} \mathrm{S}$. Note that for the fitting windows that have been used to retrieve far-red SIF with SCIAMACHY, coadding of pixels was done on board, resulting in a degraded spatial resolution of $240 \mathrm{~km}$ cross track by $30 \mathrm{~km}$ along track. We use the SciaL1c command-line tool software package (DLR, 2006) to apply all available corrections and calibrations to generate level 1B data.

\section{Simulated radiances and irradiances}

To test the algorithm and accurately quantify retrieval errors, we use radiance simulations over a wide range of conditions similar to those used by Joiner et al. (2013) and Guanter et al. (2015) but now including wavelengths in and surrounding the $\mathrm{O}_{2} \gamma$ band. Here, we provide a brief overview of the simulated data. Top-of-the-atmosphere (TOA) radiances are computed using the Matrix Operator Model (MOMO) radiative transfer model (Fell and Fischer, 2001; Preusker and Lindstrot, 2009) with absorption line parameters from the high-resolution atmospheric radiance and transmittance model code (HITRAN) 2008 data set (Rothman et al., 2009). The monochromatic sun-normalized radiances are sampled at $0.005 \mathrm{~nm}$. They are then multiplied by a solar spectrum sampled in the same way and finally convolved with various instrument line shape functions and resampled. As in Joiner et al. (2013), we use solar data from http://kurucz.harvard. edu/sun/irradiance2005/irradthu.dat, similar to Chance and Kurucz (2010) but more highly sampled.

Rotational Raman scattering (RRS) is not included in the simulation. RRS is relatively small at the $\mathrm{O}_{2} \mathrm{~B}$-band wavelengths (Vasilkov et al., 2013). We expect that RRS will also be small within the less deep feature of the $\mathrm{O}_{2} \gamma$ band even though the amount of RRS will increase somewhat with the decrease in wavelength. We also expect that with real data, the effects of RRS may be partially accounted for within our PCA retrieval framework discussed below as they are not purely additive but also contain a multiplicative component. The effects of vibrational Raman scattering (VRS) in the atmosphere are expected to be much smaller than those of RRS at these wavelengths and therefore not important (Lampel et al., 2015). Directional effects of the vegetation reflectance and fluorescence are also not simulated, but the impact on SIF retrievals is expected to be limited as discussed below.

Radiances are computed for a range of view and solar zenith angles (SZAs), atmospheric temperatures, humidities, aerosol profiles, and surface pressures as discussed in Joiner et al. (2013). Two separate data sets are created, one without fluorescence intended for principal component analyses (referred to as "training") and one containing fluorescence intended to examine retrieval performance (referred to as "testing"). There are 60 possible top-of-canopy fluores- cence spectra from various combinations of chlorophyll content and leaf area index as shown in Joiner et al. (2013). We used only combinations that produced fluorescence values of $<1 \mathrm{~mW} \mathrm{~m}^{-2} \mathrm{~nm}^{-1} \mathrm{sr}^{-1}$ at $682 \mathrm{~nm}$, consistent with GOME2 and SCIAMACHY satellite observations shown below. There are a total of 38400 and 15655 different samples in the training and testing data sets, respectively.

\section{Retrieval methodology}

We performed several types of red SIF retrievals using both real satellite data and simulations. The first type of retrieval relies solely upon the filling-in of SFLs by SIF. This approach was used by Joiner et al. (2013) for far-red SIF retrievals and Guanter et al. (2015) for simulated TROPOMI red SIF retrievals employing a relatively small fitting window $(682-686.5 \mathrm{~nm})$. This window is similar to the one used by Wolanin et al. (2015) in a differential optical absorption spectroscopy (DOAS) type of retrieval applied to GOME-2 and SCIAMACHY. We refer to this approach as the SFL red SIF retrieval.

The second type of retrieval, referred to as the $\mathrm{O}_{2}$-band retrieval, is used to estimate terrestrial red SIF and expands the spectral fitting windows of the SFL retrievals to encompass the $\mathrm{O}_{2} \gamma$ and $\mathrm{B}$ bands. The difficulty in using these absorption bands for satellite retrievals is that their depth (in the absence of SIF filling-in) must be accurately characterized in order to estimate the filling-in due to SIF. Their depth can be altered by aerosols, clouds, surface pressure, and the surface reflectance. The FLEX approach for utilizing these bands is to perform an atmospheric correction to estimate the bottom of atmosphere radiance using data from FLEX itself as well as measurements from the Sentinel-3 satellite that will fly in tandem (Cogliati et al., 2015). Here, we provide an alternative method.

We propose using the $\mathrm{O}_{2} \gamma$ band, which is not affected by SIF filling-in, to characterize the depth of the $\mathrm{O}_{2}$ B band in the absence of SIF. As will be demonstrated below (see Sect. 4.2), principal component analyses when computed using both bands together show that in the absence of SIF, the depths of the $\mathrm{O}_{2} \gamma$ and $\mathrm{B}$ bands are highly correlated; a very high fraction of the spectral variability of both bands can be described by just a couple of principal components, representing absorption from both $\mathrm{O}_{2}$ and $\mathrm{H}_{2} \mathrm{O}$ columns in the atmosphere. This is aided by the fact that over land (as is the case for clouds over ocean), the reflectance of both bands is very similar, leading to a predictable B-band depth if that of the $\gamma$ band is measured.

As will be demonstrated with simulated data (see Sect. 5.2 for details), when SIF is present, additional information on the filling-in of the $\mathrm{O}_{2} \mathrm{~B}$ band by SIF can in effect be gleaned from the filling-in of SFLs. This is because SIF (ignoring instrumental artifacts) is the primary source of filling-in of these lines. Therefore, the filling-in derived from the $\mathrm{O}_{2}$ 
B-band part of the spectrum should be consistent with the filling-in of SFL within a spectral fit that covers both features. Therefore, both the $\gamma$ band and filling-in of SFLs can be used to help estimate the band depth of the B band and disentangle this from the filling-in effect of SIF. We accomplish this by simultaneously fitting the $\mathrm{O}_{2} \gamma$ and B bands and the SFLs using a combination of principal components that account for variations in spectral depth of the oxygen bands in the absence of SIF as well as the filling-in of SFLs and the $B$ band by SIF.

The potential advantage of using the $\mathrm{O}_{2}$ bands is that this may offer some noise reduction as compared with what can be achieved by using only the filling-in of SFLs. This is important for the difficult measurement of the very small red SIF signal. As described below, both $\mathrm{O}_{2}$ bands may be additionally filled in by RRS and VRS. However, this filling-in may be small to negligible in these bands and, even if measurable, may be at least partially accounted for by our principal component analysis approach. The fitting windows for our $\mathrm{O}_{2}$-band retrievals are $622-640 \mathrm{~nm}$ for the $\mathrm{O}_{2} \gamma$ and two different windows for the $\mathrm{O}_{2} \mathrm{~B}$ band, either $682-692$ or $682-$ $698 \mathrm{~nm}$.

Oceanic red SIF can be retrieved using the filling-in of SFLs (Wolanin et al., 2015), the continuum red SIF emission which can be measured above the dark ocean surface (Abbott and Letelier, 1999), or both, as will be shown here. Here, we selected the spectral window of $660-713 \mathrm{~nm}$ for ocean SIF retrievals. This window exploits the continuum SIF emission that includes both sides of the $683 \mathrm{~nm}$ feature. This emission can be cleanly detected over the relatively dark ocean surface as proven by the use of the broadband MODIS sensor to measure it (Hu et al., 2005). Use of the large fitting window encompassing the red SIF emission feature is not only feasible for oceanic fluorescence retrievals, owing to the otherwise relatively dark ocean surface, but also beneficial. Firstly, fitting the peak as well as both shoulders of the red SIF emission feature allows for a clean separation of its spectral structure with that of monotonically decreasing or otherwise independent spectral effects such as those produced by water leaving radiance, atmospheric scattering and absorption, RRS in the atmosphere, and VRS in the ocean. Secondly, use of this large fitting window also reduces the impact of instrumental noise and other artifacts such as nonlinearity effects that impact the small radiance levels typically measured over ocean. The $\mathrm{O}_{2} \gamma$ band is not needed or used here for the oceanic SIF retrievals.

\subsection{General approach}

The basic idea behind our approach is similar that used by Joiner et al. (2013). The key is to separate the spectral features of sun-normalized TOA radiances or reflectances $\left(\rho_{\text {tot }}\right)$ as a function of wavelength $\lambda$ related to (1) atmospheric absorption (i.e., the total irradiance transmittance $\mathcal{T}$ and the spherical transmittance from surface to TOA, $\overline{\mathcal{T}}$ ), (2) surface reflectivity $\left(\rho_{\mathrm{s}}\right)$, and (3) SIF radiance emitted at the surface. Neglecting the effects of atmospheric Rayleigh scattering, which was shown to be appropriate in this context (Joiner et al., 2013), we have

$\rho_{\text {tot }}(\lambda)=\rho_{\mathrm{s}}(\lambda) \mathcal{T}(\lambda) \overline{\mathcal{T}}(\lambda)+\frac{\pi \operatorname{SIF}(\lambda) \overline{\mathcal{T}}(\lambda)}{E(\lambda) \cos \left(\theta_{0}\right)}$,

where $\theta_{0}$ is the SZA, and $E(\lambda)$ is the observed extraterrestrial solar irradiance. Joiner et al. (2013) showed that $\overline{\mathcal{T}}(\lambda)$ could be estimated using

$\overline{\mathcal{T}}(\lambda)=\exp \left(\ln \left[\mathcal{T}_{2}(\lambda)\right] \frac{\sec (\theta)}{\sec (\theta)+\sec \left(\theta_{0}\right)}\right)$,

where $\theta$ is the view zenith angle, and $\mathcal{T}_{2}(\lambda)=\mathcal{T}(\lambda) \overline{\mathcal{T}}(\lambda)$ is the sun-to-satellite (two-way) atmospheric transmittance. This amounts to the assumption of the so-called geometrical air mass factor within the DOAS formulation that is appropriate for a non-scattering, linearly absorbing atmosphere. $\rho_{\mathrm{S}}(\lambda)$ and $\operatorname{SIF}(\lambda)$ represent TOA spectral components of surface reflectance and fluorescence modified by atmospheric scattering (cloud, aerosol, and Rayleigh) that is spectrally smooth. In other words, atmospheric scattering is implicitly accounted for within these terms. As both Rayleigh scattering and aerosols are included in our simulation data set, we can evaluate their impact on the retrievals. Equation (1) also assumes a Lambertian surface. The implications of this assumption are discussed below.

Here, we model the fluorescence red emission feature as a function of wavelength as having a Gaussian shape similar to, e.g., Subhash and Mohanan (1997) and Zarco-Tejada et al. (2000), i.e.,

$\operatorname{SIF}(\lambda)=A \exp \left(\frac{\left(\lambda-\lambda_{0}\right)^{2}}{2 \sigma^{2}}\right)$

where $A$ is the SIF magnitude at the peak emission given in radiance units. For the red fluorescence emission feature, we use $\lambda_{0}=683 \mathrm{~nm}$. Over ocean, we found that a value for the Gaussian standard deviation, $\sigma$, of $9.55 \mathrm{~nm}$ provided a good fit to observations. Over land, we found that interference from the far-red SIF emission feature may necessitate the use of different values of $\sigma$, depending on the size of the spectral fitting window as discussed below.

As in Joiner et al. (2013), we assume that $\rho_{\mathrm{S}}(\lambda)$, within our limited spectral fitting window, is spectrally smooth and model it as a low-order polynomial in $\lambda$. While other representations for fluorescence and reflectance have been explored (e.g., Mazzoni et al., 2010, 2012), small errors in the assumed shape of the fluorescence emission will likely have little impact on the estimated peak fluorescence value (Daumard et al., 2010; Fournier et al., 2012; Guanter et al., 2013). We estimate the spectral structure of $\mathcal{T}_{2}$ using PCs as described below. 


\subsection{Generation of atmospheric PCs}

Here, we use a data-driven approach to estimate $\mathcal{T}_{2}(\lambda)$ in Eq. (2). We perform a PCA to represent $\mathcal{T}_{2}(\lambda)$, similar to the approach of Joiner et al. (2013) and Köhler et al. (2015), i.e.,

$\mathcal{T}_{2}(\lambda)=\sum_{i=1}^{n} a_{i} \phi_{i}(\lambda)+1$,

where $\phi_{i}(\lambda)$ are the PCs and $a_{i}$ are the coefficients of the PCs. In place of laboratory-measured absorption cross sections as is typical in the DOAS approach, we are essentially using atmospheric spectra (simulated or measured) to derive the spectral components of atmospheric absorption. This approach has the following advantages: (1) it does not require knowledge of the instrument response function and (2) it implicitly captures instrumental artifacts such as drifts and imperfections in the wavelength calibration. In contrast, the PCs may mix instrumental effects with real atmospheric phenomena in the orthogonal PCs. This does not allow for a clean analysis of instrumental artifacts or accuracy of the radiative transfer. In addition, the approach may not work well if an unrepresentative sample is used to generate the PCs.

For comparison, we performed PCAs with both the simulation training data and actual GOME-2 radiances. For the GOME-2 PCA, we use spectra from a single day consisting of observations over sea ice, snow/ice-covered land, the Sahara desert, and cloudy ocean (avoiding continental coastlines) for pixels with $\theta_{\mathrm{o}}<70^{\circ}$ and geometrical air mass factors, $\mathrm{GAMF}=\sec (\theta)+\sec \left(\theta_{\mathrm{O}}\right),<5$. The precise areas used are shown in the Supplement. We compute the reflectance at $670 \mathrm{~nm}\left(\rho_{670}\right)$ and use ocean observations only for $\rho_{670}>0.7$ and Sahara pixels only for $\rho_{670}>0.52$.

Joiner et al. (2013) used the logarithm of the normalized radiance spectra as is typical in DOAS implementations. Here, we work with the normalized radiances rather than the logarithm of the normalized radiance as this works just as well. For both real and simulated data, we normalize the spectra with respect to second-order polynomials fit to wavelengths not significantly affected by atmospheric absorption (i.e., $620<\lambda<625 \mathrm{~nm}, 635<\lambda<640 \mathrm{~nm}, 680<$ $\lambda<687 \mathrm{~nm}, 712<\lambda<713 \mathrm{~nm})$. This essentially produces atmospheric transmittance spectra. We then subtract unity before conducting the principle component analysis to produce values of zero in the absence of atmospheric absorption. The value of unity is then added back in the retrieval step once the coefficients of the PCs are determined in order to compute the two-way transmittance. In the strict implementation of PCA, a mean spectrum is computed and subtracted from each individual spectrum. We found that this is not necessary and in fact further complicates the approach. When the mean is not subtracted, the first PC represents the mean atmospheric transmittance.

Note that we use a slightly larger $\mathrm{O}_{2} \mathrm{~B}$-band window for the PCA as compared with the retrieval. The larger PCA window is needed to fit the radiances not affected by strong $\mathrm{O}_{2}$ or $\mathrm{H}_{2} \mathrm{O}$ absorption so that atmospheric transmittance may be accurately computed. The leading principal components are related to atmospheric absorption from oxygen and water vapor as well as instrumental effects such as wavelength shifts that span this full wavelength range. Testing with simulation data confirms that using a larger fitting window for the PCA as compared with the retrieval does not present problems. In other words, we are able to use smaller fitting windows for SIF retrievals that are contained within the larger one used for the PCA.

One key difference with respect to the approach used by Joiner et al. (2013) is that here we use two separate and disconnected spectral regions, encompassing the $\mathrm{O}_{2} \gamma$ and $\mathrm{B}$ bands, to retrieve SIF in the red emission feature over land. For these two fitting windows, a single PCA is performed that covers both fitting windows. The purpose of the PCA is to relate the absorption in the $\mathrm{O}_{2} \gamma$ and $\mathrm{B}$ bands in the absence of fluorescent emissions. Then, in the retrieval step the $\mathrm{O}_{2} \gamma$ band is used to disentangle the spectral structure of absorption and fluorescence within the $\mathrm{O}_{2} \mathrm{~B}$ band. This is done simultaneously with the retrieval of red SIF and the surface spectral reflectance. Equation (2) is used to estimate how much of the SIF emission is absorbed within the atmosphere as it travels towards the satellite sensor.

Figure 2 shows the leading four PCs; each PC covers the wavelength ranges $622-640$ and $680-713 \mathrm{~nm}$ that encompass the $\mathrm{O}_{2} \gamma$ and $\mathrm{B}$ bands, respectively, and these ranges are shown in separate panels for each PC. The PCs are computed with simulated data for FWHMs of $0.5 \mathrm{~nm}$ (similar to GOME-2) and $0.3 \mathrm{~nm}$ as well as with actual GOME-2 data from 1 July 2012. The spectral variance in these windows is due to both oxygen and water vapor absorption. The variances explained (with respect to the total) as well as the cumulative variances explained are indicated. The PCs for the simulated data are similar for the two spectral resolutions with more fine-scale structure, particularly in the oxygen B band, at the higher resolution. The variance explained by the leading PCs is similar for the simulated data at the two spectral resolutions and for GOME-2 data, with slightly more variance explained per PC for GOME-2 data. The first PC explains over $96 \%$ of the spectral variance. More than $99.97 \%$ of the variance is captured in the first four modes for both the simulated and GOME- 2 data.

The PCs for simulated and real data are not expected to be identical. PCs from the real data may contain instrumental artifacts and processes not included in the simulated data (e.g., RRS). In addition, the simulated data may not represent all of the conditions or the distribution of conditions that are present in the GOME-2 data. It is nevertheless remarkable how similar the leading PCs are in the simulated data as compared with the GOME-2 data. 

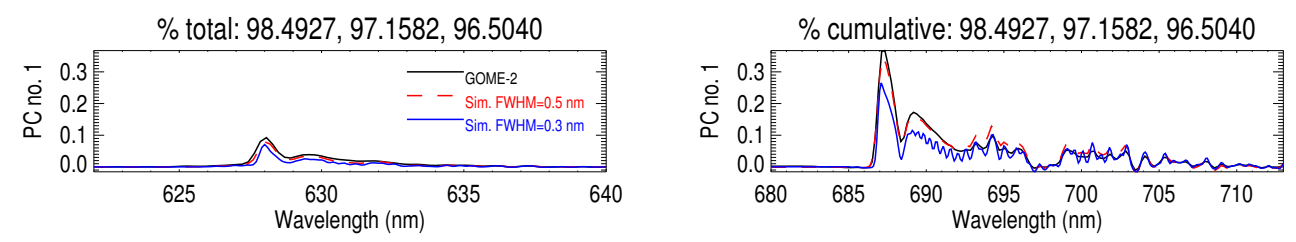

\% total: $1.4687,2.7487,3.3809$
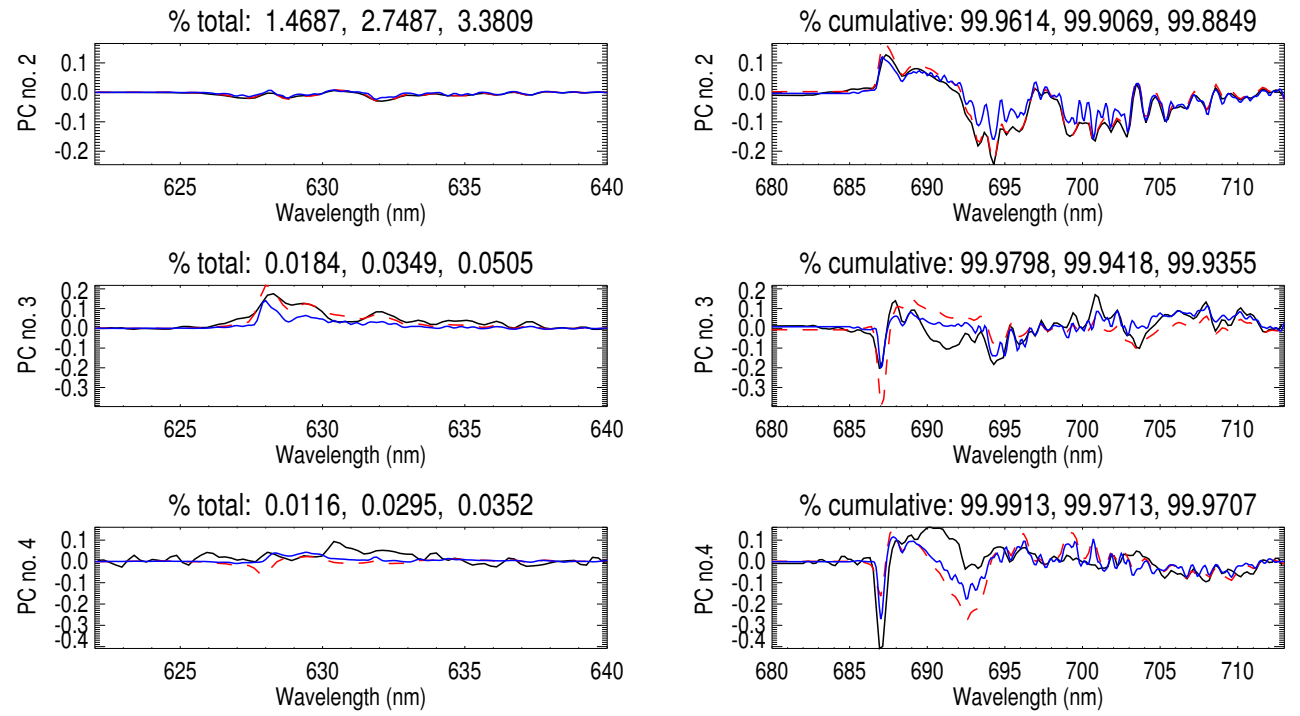

Figure 2. Leading principal components (PCs) of simulated (Sim.) and actual GOME-2 reflectance spectra (from 1 July 2012 , black) for spectral windows encompassing the oxygen $\gamma$ band (left panels) and B band (right panels). Simulated data are for a GOME-like instrument (red lines) with FWHM $=0.5 \mathrm{~nm}$ (red) and a higher spectral resolution instrument with FWHM $=0.3 \mathrm{~nm}$ (blue); numbers in the top titles are the variance explained in terms of percent of the total and cumulative percent of the total with numbers for GOME-2, simulated $\mathrm{FWHM}=0.5 \mathrm{~nm}$, and $\mathrm{FWHM}=0.3 \mathrm{~nm}$, respectively.

\subsection{Solving the nonlinear problem}

As described in Joiner et al. (2013), we use a gradientexpansion algorithm to solve the nonlinear estimation problem using a forward model based on Eqs. (1)-(4). The observation vector for each pixel consists of sun-normalized radiances in two separate windows, encompassing the $\mathrm{O}_{2} \gamma$ and $\mathrm{B}$ bands. In general, the state vector consists of (1) coefficients of the PCs, (2) separate sets of coefficients for surface reflectance polynomials in the two windows, and (3) either the peak value of the red fluorescence feature centered at $\sim 683 \mathrm{~nm}$ for $\mathrm{O}_{2}$ band retrievals or an averaged value of SIF over the SIF fitting window for SFL retrievals. For all results shown in the remainder of this paper, SIF represents a single value that refers to either the peak value or an average over the fitting window as appropriate for the red or farred emission features. At convergence, the partial derivatives contained in the Jacobian $\mathbf{K}$ matrix may be used to compute errors from an unconstrained linear error estimation, i.e.,

$\mathbf{S}_{\mathrm{r}}=\left(\mathbf{K}^{T} \mathbf{S}_{\mathrm{e}}^{-1} \mathbf{K}\right)^{-1}$,

where $\mathbf{S}_{\mathrm{r}}$ is the retrieval error covariance matrix, and $\mathbf{S}_{\mathrm{e}}$ is the measurement error covariance (e.g., Rodgers, 1990).
Specifically, the state vector of the SFL red SIF terrestrial retrievals consists of coefficients for a third-order polynomial to model the surface reflectivity, coefficients for three PCs, and a mean value of SIF across the small fitting window (i.e., the Gaussian shape for SIF emission is not needed or used). In contrast, the state vector for the more complex $\mathrm{O}_{2}$ terrestrial red SIF satellite retrievals includes coefficients of $15 \mathrm{PCs}$, coefficients of a fourth-order polynomial for surface reflectivity in each $\mathrm{O}_{2}$ fitting region, and the peak value of SIF at $683 \mathrm{~nm}$, assuming a Gaussian shape for SIF emissions at red wavelengths. The fitting windows used for GOME-2 and SCIAMACHY were $622-640 \mathrm{~nm}$ for the $\mathrm{O}_{2}$ $\gamma$ band region and two different fitting windows between 682 and $698 \mathrm{~nm}$ for the B-band region. For the $\mathrm{O}_{2}$-band retrievals, each PC covers both the $\mathrm{O}_{2} \gamma$ and B bands. We used $\lambda_{0}=683 \mathrm{~nm}$ and $\sigma=10$ for the satellite retrievals. The selection of these parameters will be discussed in more detail below.

The polynomial model for surface reflectivity can account for atmospheric scattering (Rayleigh and aerosol); the polynomial coefficients represent an effective surface reflectivity rather than the true surface reflectivity. This effective surface reflectivity includes the spectrally smooth effects of atmospheric scattering. In addition, this formulation can also ac- 
count for the effects of non-Lambertian surface reflectance. In this case, the retrieved coefficients will produce a reflectivity either higher or lower than that of a Lambertian surface. The resulting interaction with atmospheric scattering will still produce a spectrally smooth function of wavelength that can be represented with a polynomial function. There should be virtually no impact on the retrieved SIF in this case. For non-Lambertian SIF, we will simply retrieve and report the SIF radiance for the given geometry. This value may be different from a retrieval obtained for a different viewing geometry.

For oceanic retrievals, coefficients of eight PCs are retrieved along with those of a second-order polynomial to account for the spectral dependence of the water leaving radiance. The fitting window $660-713 \mathrm{~nm}$ spans the range of significant red SIF emissions. We use Eq. (3) with $\lambda_{0}=683 \mathrm{~nm}$ and $\sigma=9.55$ for oceanic SIF emissions. By trial and error, we found that these parameter values provide adequate fits to the observed radiances over ocean.

\subsection{Processing of GOME-2 and SCIAMACHY data}

The overall processing of the satellite data follows the approach detailed in Joiner et al. (2013), which is augmented as described in this section. Figure 3 shows a flow diagram of the basic steps. One subset of radiance data is used to generate the PCs (chosen such that fluorescence is not present). We perform a PCA daily using a single measured solar irradiance spectrum per day. Similar to Joiner et al. (2013), we use pixels over highly cloudy ocean and snow- and ice-covered surfaces $\left(\rho\right.$ at $670 \mathrm{~nm}>0.7$ and SZA $\left.<70^{\circ}\right)$ and the Sahara for the PCA. The derived PCs are then used for the fluorescence retrieval. Quality assurance checks (see Sects. 4.4.2-4.4.3) are then conducted to filter out noisy radiance data, cloudy data, and failed retrievals (see also Joiner et al., 2013). Adjustments are also made to remove biases (see Sects. 4.4.1 and 4.4.4). Finally, the quality-controlled retrievals are gridded at a monthly temporal and $1^{\circ}$ (or other as noted) spatial resolution to produce level 3 data sets.

Ideally, the last step is validation of the level 2 or 3 data sets. There are very few opportunities for validation available. Yang et al. (2015) compared ground-based data with far-red SIF from GOME-2 for a season over one forested location. However, in general, it is difficult to compare groundbased data with large pixel satellite data due to the spatial mismatch. Aircraft-based data are extremely limited at the current time. One of the few tools available for global validation is intercomparison of different satellite data sets as in Joiner et al. (2013), Köhler et al. (2015), and Khosravi et al. (2015), which is the approach undertaken here.

\subsubsection{Absolute solar calibration drift}

Many instrumental calibration issues cancel out when using the ratio of the Earth radiance to the solar irradiance (i.e.,

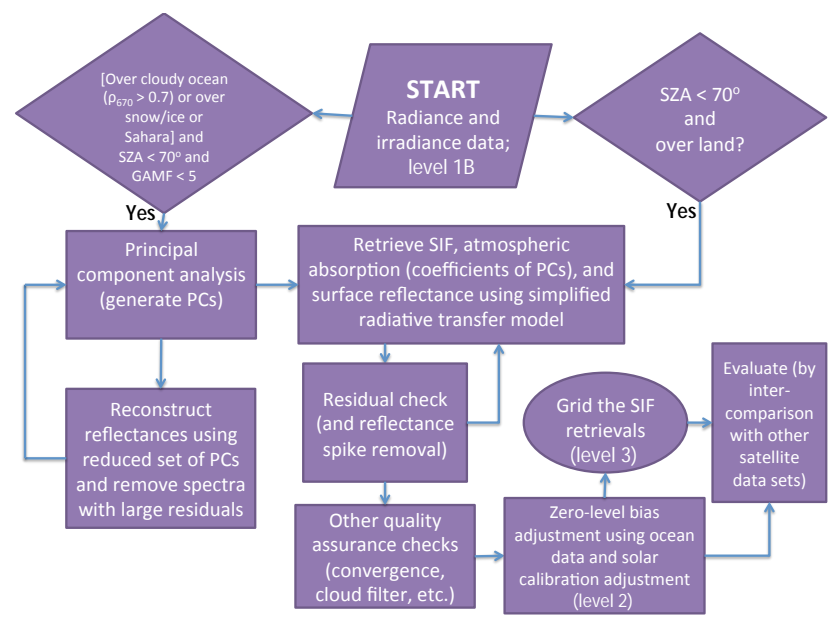

Figure 3. Flow diagram of the basic steps used to produce SIF data sets.

reflectances) in Eq. (1). For example, the reflectance degradation factor at the wavelengths of interest for GOME-2 SIF retrievals is reported to be only a few percent over the course of the MetOp-A mission (Tilstra et al., 2012). Other types of degradation can also occur that may or may not cancel the reflectances. Wavelength shifts and changes in the spectral bandpass can change over time (Dikty et al., 2012). For GOME-2, changes in the instrument bandpass occurred primarily in the UV channels of the instrument. Even so, this type of degradation should be handled within our algorithm with use of the PCA. However, there are still some unexplained instrument behaviors for GOME-2, such as the dependence of the dark signal on temperature (Dikty et al., 2012), that may not be fully accounted for within our algorithm or zero-level adjustment scheme and will lead to systematic errors in SIF retrievals. Various other instrumental effects that may produce false signatures in SCIAMACHY SIF retrievals are documented in Lichtenberg (2006). Their potential impact on SIF retrievals is discussed in Joiner et al. (2012). An approach to mitigate the resulting biases in SIF retrievals is detailed in Sect. 4.4.4.

As compared with pure DOAS retrievals used for trace-gas retrievals, SIF retrievals are more sensitive to the absolute calibration of the solar irradiance data (see Eq. 1). MetOpA GOME-2 has encountered radiometric degradation over its lifetime. We have made adjustments to the SIF retrievals based on irradiance changes that occurred at $690 \mathrm{~nm}$. We fit a second-order polynomial to these irradiances as a function of time after accounting for variations in the sun-Earth distance. These changes are of the order of $15 \%$ and occurred primarily over the first 6 years of the mission with stabilization after that. 


\subsubsection{Cloud filtering and quality control}

As detailed in Joiner et al. (2012), we compute an effective cloud fraction $f_{\mathrm{c}}$. Neglecting scattering, it is derived using

$f_{c}=\frac{R_{\mathrm{obs}}-R_{s}}{0.8-R_{s}}$,

where $R_{\mathrm{obs}}$ is the retrieved surface reflectivity (assuming no atmospheric scattering) at the shortest wavelength in the fitting window, and $R_{s}$ is the black-sky 16-day gridded filled land-surface albedo product from Aqua MODIS (MOD43B3) at $656 \mathrm{~nm}$ (Lucht et al., 2000). When computing monthly SIF averages, we eliminate data with $f_{\mathrm{c}}>0.3$, consistent with that used in version 26 far-red GOME-2 SIF level 3 product provided at http://avdc.gsfc.nasa.gov. The choice of the cloud threshold is empirical. Our selection of 0.3 is a more stringent threshold than that used by Joiner et al. (2013) and Köhler et al. (2015) and results in somewhat noisier results due to a decrease in sampling. Köhler et al. (2015) showed that magnitudes of gridded SIF decrease with increases in the cloud cover threshold but that the overall temporal variations remain consistent.

Simulations show that a substantial fraction of the satellite SIF signal can still be detected even through moderately cloudy conditions (Frankenberg et al., 2012). Use of more or less stringent limits on cloud contamination within a moderate range did not substantially alter the derived spatial and temporal patterns of red SIF. However, placing stricter limits decreases the number of samples included in a gridded average. This reduces coverage and increases noise in gridded SIF averages.

In the results shown below, we include all data that passed gross quality assurance checks on the retrieval convergence and radiance residuals. These checks typically remove few observations. We also eliminate all data with $\mathrm{SZA}>70^{\circ}$.

\subsubsection{Radiance spike removal}

The South Atlantic Anomaly (SAA) increases noise in observed radiances in the vicinity of South America over southern Brazil and surrounding areas, particularly for GOME-2 measurements but also present in SCIAMACHY radiances (Köhler et al., 2015; Wolanin et al., 2015). In an effort to mitigate the effects of this noise, the following steps are taken. A first step PCA is conducted as outlined above. Then, for each observation, the spectrum is reconstructed using a reduced number of PCs. In this work, we use 20 PCs. The maximum error for each reconstructed spectrum is then computed. Any spectrum with maximum error $>0.5 \%$ is discarded from the sample. The PCA is performed again using only the spectra passing this quality control check. Typically, only a very small fraction of spectra are removed from the sample during this process.

A radiance outlier check is also performed during the retrieval process as follows. A first step retrieval is per- formed using all radiances within the specified fitting window. Following the retrieval, radiance residuals (observed minus computed from the retrieval) are calculated. If any radiances residuals are $>0.5 \%$, those wavelengths are then given a weight of 0 in a second step retrieval. If for a given observation, more than half of the wavelengths have radiance residuals $>0.5 \%$, that observation is flagged. Again, only a very small percentage of spectra are flagged in this process.

\subsubsection{Zero-level adjustment}

Köhler et al. (2015) found that GOME-2 and SCIAMACHY far-red SIF retrievals exhibited biases, henceforth referred to as zero-level offsets, in the PCA training data set (expected to have a mean near 0 ) of the order of several tenths

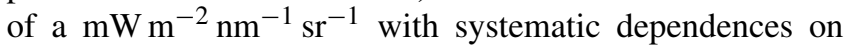
latitude. The biases were higher for GOME-2 as compared with SCIAMACHY by a factor of 2 or more and the dependences on latitude for the two instruments were different. Joiner et al. (2012) also found zero-level offsets for SCIAMACHY at $866 \mathrm{~nm}$. Khosravi et al. (2015) showed that for SCIAMACHY in the far-red wavelength range, an additive radiance signal that leads to the zero-level offsets was relatively stable over time and a fairly linear function of radiance. The bias was shown to be of the same order of magnitude as the SIF signal. These artifacts result from unaccounted for dark current, stray light, so-called memory effects, and other nonlinear responses (e.g., Joiner et al., 2012). All of these additive effects can produce a false filling-in of SFLs and absorption lines which can have a significant impact on terrestrial SIF retrievals. Because the effects are additive, they are not well captured by the leading principal components and this leads to biases with a spatial dependence.

We developed an empirical correction scheme to mitigate zero-level offsets. This scheme is implemented in version 26 GOME-2 data that are publicly available at http: //avdc.gsfc.nasa.gov. We use the same correction scheme to adjust red SIF terrestrial retrievals here. The zero-level adjustment scheme is designed to account for instrumental nonlinear radiance behavior that appears to slightly distort the spectra as a function of radiance. The scheme may also correct for small effects of RRS in the atmosphere. As shown below, we find that the biases vary with time (on both daily and monthly timescales) and instrument.

The zero-level adjustment scheme has the following steps. (1) It provides a training data set of retrievals in which SIF should be 0 (over all areas of the ocean passing all quality control checks except the cloud filtering check for a single day). (2) Within a given latitude range, using a least squares approach, it determines coefficients (A through $\mathrm{H}$ ) to the following regression model:

$$
\begin{aligned}
\epsilon_{\mathrm{a}} / \cos \left(\theta_{0}\right)= & A+B \theta_{0}+C \theta_{0}^{2}+D \theta_{0}^{3} \\
& +E I_{1}+F I_{1}^{2}+G I_{1}^{3}+H \text { lat }
\end{aligned}
$$


where $\epsilon_{\mathrm{a}}$ is the additive radiance component not due to SIF, $I_{1}$ is the radiance at a wavelength not impacted by strong $\mathrm{O}_{2}$ absorption (e.g., $682.5 \mathrm{~nm}$ ), lat is latitude, and $\epsilon_{\mathrm{a}}$ has been normalized by $\cos \left(\theta_{0}\right)$ to remove its dependence upon the top-of-atmosphere solar irradiance. We found empirically that this model accounts for much of the variability in the bias. (3) It computes the normalized zero-level bias, $\epsilon_{\mathrm{a}} / \cos \left(\theta_{0}\right)$, using the derived regression coefficients (A through $\mathrm{H}$ ) for each pixel over land, subtracted from the similarly normalized SIF retrieval, then multiplied by $\cos \left(\theta_{0}\right)$ to obtain the corrected estimate of SIF. The regression is not extrapolated beyond the range of $I_{1}$ and $\theta_{0}$ values found in the training sample data set. The regression coefficients are generated separately for different latitude bins. For GOME-2 v26 far-red SIF retrievals, we use latitude bins bounded by $90,45^{\circ} \mathrm{S}$ and $0,45,90^{\circ} \mathrm{N}$. For SCIAMACHY red SIF retrievals, we use latitudes bins bounded by $90^{\circ} \mathrm{S}$ and $0,90^{\circ} \mathrm{N}$ and for GOME- 2 red SIF retrievals $90,40^{\circ} \mathrm{S}$ and $40,90^{\circ} \mathrm{N}$. The ranges were chosen empirically (by trial and error) for each instrument and retrieval type to minimize discontinuities at the boundaries and to maximize the ability to remove zero-level offsets.

The Supplement shows examples of how biases over ocean vary as a function of latitude, $\theta_{0}$, and radiance $\left(I_{1}\right)$ for 2 randomly selected days in July 2007. Also shown are the biases after the correction scheme is applied. Results are shown for SCIAMACHY SFL and $\mathrm{O}_{2}$-band retrievals as well as $\mathrm{O}_{2}$ band retrievals from GOME-2. The biases are shown to vary with day and instrument as well as the parameters in the correction scheme. The bias correction works well in most cases but may not be effective at high radiance values that can be scarce over ocean in certain latitude bins and thus do not receive much overall weight in the least squares fitting.

The zero-level adjustment scheme essentially uses ocean data with the assumption of negligible SIF emissions. While this is a good assumption for far-red SIF, there is significant SIF emission in the red SIF region in some areas over ocean as shown below. We did not make any attempt to avoid these areas for the zero-level adjustment scheme. Our regression model assumes that the zero-level adjustment is a smooth function of radiance. As radiance increases from the clearsky dark to cloudy skies, the ocean SIF signal becomes more shielded. Note that reflectances over land tend to be higher than those over the dark ocean at red wavelengths, so that adjustments over land will typically be made using cloudy ocean data.

We found that after applying the derived regression model over ocean, the spatial patterns of oceanic SIF are still present; this indicates that our regression model has not completely removed these signals. However, there may be a slight overcorrection in our approach for the red SIF zero-level adjustment. Figure S10 of the Supplement shows an example of red SIF retrievals for May 2007 with and without zerolevel adjustment over both land and ocean. For comparison, we also show oceanic SIF obtained with the full band re- trievals that are less susceptible to zero-level offsets. In fact, we did not find a significant zero-level offset in the ocean SIF retrievals as we did with the terrestrial retrievals. This is because the ocean retrievals rely more on the broadband emission rather than filling-in of SFLs; this filling-in is more sensitive to false filling-in by effects such as stray light, dark current, and Raman scattering (oceanic or atmospheric). We therefore do not apply any zero-level adjustment over ocean. For future versions of the zero-level offset scheme, we intend to explore a two-step regression approach whereby we first remove the oceanic SIF signal using full-band ocean retrievals before computing regression coefficients. We also have not added barren land to the regression scheme in the present version in order to test how well the scheme works using only cloudy ocean data; the addition of barren land data can easily be accomplished in a future version. As will be shown below, exclusion of barren land data from the bias adjustment parameter determination may lead to biases over very bright land surfaces, particularly over the Sahara where radiance levels are high. These high radiance values may not be well represented in the ocean data samples in a given latitude bin during certain months when convection is not prevalent within the bin.

\section{Sensitivity analysis for terrestrial red SIF}

In this section, we retrieve terrestrial red SIF using the radiances that were computed from the simulation testing data set that contains 15655 different sets of conditions. This set of conditions includes the so-called "true" SIF that serves as the benchmark for the retrieved SIF. Instrument noise is added to the simulated radiances as indicated, where the noise is uncorrelated between channels and follows a Gaussian distribution. The nominal SNR (referred to as "nom." in Table 1), specified as a function of radiance, is similar to that used by Guanter et al. (2015) for GOME-2 with SNR values of 673 and 4053 at radiances of 10 and $240 \mathrm{~mW} \mathrm{~m}^{-2} \mathrm{~nm}^{-1} \mathrm{sr}^{-1}$, respectively. Table 1 provides statistics on the differences between the retrievals and the true states for several scenarios described below. To compare true and retrieved SIF, we average SIF over the wavelength range of the red spectral fitting window.

We checked that the addition of a constant value to the simulated radiances in order to produce a zero-level offset results in a retrieved bias of the same amount. We note below that the derived zero-level offset with real satellite data is not a constant, but in fact has complex dependences on time, latitude, geometry, and radiance. We did not attempt to add this complexity to the simulations. This constant zero-level offset would be detected and corrected by our bias adjustment scheme. 
Table 1. Statistical comparison of retrieved versus "true" values of SIF obtained with the simulated testing data set for different experiments (Exp); all fluorescence radiance units (indicated by *) are $\mathrm{mW} \mathrm{m}^{-2} \mathrm{~nm}^{-1} \mathrm{sr}^{-1}$. Retrievals are performed for an instrument with a given fullwidth at half-maximum (FWHM) line shape function, signal-to-noise ratio (SNR), number of principal components (no. PCs), and fitting window from starting wavelength $\lambda_{1}$ to ending wavelength $\lambda_{2}$. Statistics given are the root-mean-square difference (RMS diff.), correlation coefficient $(r)$, mean difference (bias) of retrieved minus truth, standard deviation $(\sigma)$, and slope $(B)$ and intercept $(A)$ of a linear fit (retrieved fluorescence $=A+B$. truth) (last two columns, respectively). Under the SNR heading, "nom." refers to the nominal model described in the text.

\begin{tabular}{|c|c|c|c|c|c|c|c|c|c|c|c|c|}
\hline Exp & $\begin{array}{l}\text { FWHM } \\
(\mathrm{nm})\end{array}$ & SNR & No. PCs & $\begin{array}{l}\lambda_{1} \\
(\mathrm{~nm})\end{array}$ & $\begin{array}{l}\lambda_{2} \\
(\mathrm{~nm})\end{array}$ & $\begin{array}{l}\gamma \text { band } \\
\text { incl. }\end{array}$ & $\begin{array}{l}\text { RMS diff. } \\
\quad *\end{array}$ & $r$ & $\begin{array}{c}\text { bias } \\
*\end{array}$ & $\begin{array}{l}\sigma \\
*\end{array}$ & slope & $\begin{array}{r}\text { intercept } \\
*\end{array}$ \\
\hline 1 & 0.5 & nom. & 5 & 682.0 & 692.0 & Yes & 0.71 & 0.68 & -0.39 & 0.59 & 0.76 & -0.03 \\
\hline 2 & 0.5 & nom. & 10 & 682.0 & 692.0 & Yes & 0.63 & 0.71 & -0.06 & 0.62 & 0.90 & 0.08 \\
\hline 3 & 0.5 & nom. & 15 & 682.0 & 692.0 & Yes & 0.73 & 0.66 & -0.02 & 0.73 & 0.92 & 0.09 \\
\hline 4 & 0.5 & nom. & 10 & 682.0 & 698.0 & Yes & 0.48 & 0.75 & -0.13 & 0.46 & 0.87 & 0.03 \\
\hline 5 & 0.5 & nom. & 10 & 682.0 & 692.0 & No & 0.88 & 0.60 & -0.04 & 0.88 & 0.94 & 0.05 \\
\hline 6 & 0.5 & no noise & 10 & 682.0 & 692.0 & Yes & 0.11 & 1.00 & -0.06 & 0.09 & 0.90 & 0.08 \\
\hline 7 & 0.5 & no noise & 10 & 682.0 & 698.0 & Yes & 0.17 & 0.99 & -0.13 & 0.11 & 0.87 & 0.03 \\
\hline 8 & 0.5 & nom & 10 & 682.0 & 692.0 & $\mathrm{Yes}^{\mathrm{a}}$ & 1.46 & 0.40 & -0.34 & 1.42 & 0.88 & -0.17 \\
\hline 9 & 0.5 & no noise & 10 & 682.0 & 692.0 & No & 0.06 & 1.00 & -0.02 & 0.06 & 0.95 & 0.05 \\
\hline 10 & 0.5 & $2 \mathrm{X}$ nom. & 10 & 682.0 & 692.0 & Yes & 1.24 & 0.45 & -0.06 & 1.24 & 0.91 & 0.07 \\
\hline 11 & 0.3 & nom. & 10 & 682.0 & 692.0 & Yes & 0.37 & 0.87 & -0.11 & 0.35 & 0.87 & 0.08 \\
\hline 12 & 0.3 & nom. & 10 & 682.0 & 698.0 & Yes & 0.31 & 0.89 & -0.15 & 0.27 & 0.84 & 0.05 \\
\hline 13 & 0.1 & nom. & 3 & 682.0 & 686.5 & No & 0.19 & 0.97 & -0.08 & 0.17 & 0.95 & 0.00 \\
\hline 14 & 0.2 & nom. & 3 & 682.0 & 686.5 & No & 0.38 & 0.90 & -0.10 & 0.37 & 0.94 & -0.01 \\
\hline 15 & 0.3 & nom. & 3 & 682.0 & 686.5 & No & 0.57 & 0.80 & -0.12 & 0.56 & 0.95 & -0.03 \\
\hline 16 & 0.5 & nom. & 3 & 682.0 & 686.5 & No & 1.22 & 0.51 & -0.22 & 1.20 & 0.93 & -0.10 \\
\hline 17 & $0.3^{\mathrm{b}}$ & nom. & 3 & 682.0 & 686.5 & No & 0.74 & 0.71 & -0.13 & 0.72 & 0.94 & -0.03 \\
\hline 18 & 0.3 & nom. ${ }^{\mathrm{c}}$ & 3 & 682.0 & 686.5 & No & 0.74 & 0.71 & -0.09 & 0.73 & 0.94 & 0.01 \\
\hline 19 & 0.5 & nom..$^{\mathrm{c}}$ & 3 & 682.0 & 686.5 & No & 1.41 & 0.47 & -0.08 & 1.41 & 0.96 & -0.01 \\
\hline 20 & 0.5 & nom. & 3 & 681.8 & 685.5 & No & 1.55 & 0.59 & -0.15 & 1.54 & 0.94 & -0.02 \\
\hline
\end{tabular}

${ }^{a}$ Used a flat solar spectrum. ${ }^{\mathrm{b}}$ Sampling of $0.2 \mathrm{~nm}$ instead of $0.1 \mathrm{~nm} .{ }^{\mathrm{c}}$ Wavelength jitter of $0.01 \mathrm{~nm}$ simulated.

\subsection{Sensitivity to number of PCs used}

Here, we focus on $\mathrm{O}_{2}$-band red SIF retrievals with an $\mathrm{O}_{2} \mathrm{~B}$ band fitting window between 682 and $692 \mathrm{~nm}$ and for an instrument with FWHM $=0.5 \mathrm{~nm}$ and sampling rate of $0.2 \mathrm{~nm}$. The $\gamma$ band fitting window was $622-640 \mathrm{~nm}$. We use fourthorder polynomials to model the surface reflectivity for each fitting window. Use of a higher-order polynomial order does not significantly improve the results, while use of a lowerorder polynomial degrades results.

The first three lines of Table 1 show results for retrievals that use 5, 10, and 15 PCs. There are small biases in all cases with biases generally decreasing with increasing numbers of PCs. The improvement in both accuracy and precision is noticeable when increasing from 5 to 10 PCs and starts to level out with subsequent increases. There is virtually no change in the results when we further increase the number of PCs (not shown). There is a slight bias obtained with both the 10 and $15 \mathrm{PC}$ results as also evidenced by the deviation of the fitted slope from unity. This bias is further discussed below.

We may also compute fluorescence errors using the linear estimation method (Eq. 5) by assuming random and uncorrelated wavelength-independent radiance errors (as was the case in our simulated data) as in Joiner et al. (2013). However, the linear estimation does not account for errors that may result from using an imperfect model for the SIF spectral emissions or an imperfect forward model (e.g., that does not account explicitly for atmospheric scattering). Here, we have assumed a Gaussian shape for SIF emissions as in Eq. (3). However, interference from far-red emissions in our spectral fitting range slightly distorts the Gaussian shape. We found that it was important to apply some constraint to the SIF emissions spectral shape in order to obtain accurate retrievals, and the Gaussian function provides a reasonable approximation. To accurately evaluate errors resulting from this approach, we show results from the full end-to-end simulation in this work rather than from the linear estimation.

\subsection{Sensitivity to the fitting window and instrumental noise}

In line 4 of Table 1 , we use a larger $\mathrm{O}_{2}$ B-band fitting window $(682-698 \mathrm{~nm})$ than for results shown in lines $1-3$. With this larger fitting window, we specified $\sigma=10$ in Eq. (3) as compared with $\sigma=7.5$ that was used for the smaller fitting window. With this configuration biases increased (results are 
further from the $1: 1$ line). This is likely because the assumed Gaussian shape for red SIF emissions is more applicable to the smaller fitting window. However, as expected, the use of a smaller fitting window decreases retrieval precision ( $\sigma$ increases).

Line 5 shows results with the same $\mathrm{O}_{2}$ B-band fitting window but now without the benefit of the $\mathrm{O}_{2} \gamma$ band. Removal of the $\gamma$ band decreases precision and increases bias. However, results with no instrument noise (lines 7 and 9) show that precision improves when the $\gamma$ band is not used. Also in contrast to the results with noisy data, lines 6 and 7 show that precisions are improved with the smaller $\mathrm{O}_{2} \mathrm{~B}$-band fitting window when noise is absent and the $\gamma$ band is included. We may therefore infer that the primary benefit of the larger fitting window in the $\mathrm{O}_{2} \mathrm{~B}$ band as well as the addition of the $\gamma$ band is to beat down the effects of instrumental noise.

In order to assess how much of an impact the SFL filling has on the results, we conducted simulations using a flat solar spectrum and no instrumental noise. In other words, with simulated data we can remove the effect of SFL line filling by providing a flat solar spectrum. We cannot do this with real data. Results shown in line 8 of Table 1 indicate that there is a substantial stabilizing effect of the SFL filling for the $\mathrm{O}_{2}$ band retrievals; compared with line 2 results, both precision and accuracy of SIF retrievals degrade significantly when the filling-in effect of SFLs is not present. Note that SFL filling occurs both inside and outside the $\mathrm{O}_{2} \mathrm{~B}$ band. An additional experiment with a flat solar spectrum and without the $\gamma$ band included in the fitting resulted in poor performance with many nonconvergent retrievals.

To summarize, SIF retrieval degradation occurs when either SFLs or the $\mathrm{O}_{2} \gamma$ band are removed from the radiances used for the spectral fit. The removal of SFLs degrades the retrievals more than the removal of the $\mathrm{O}_{2} \gamma$ band. Removal of both SFLs and the $\mathrm{O}_{2} \gamma$ band results in nonconvergent or poor retrievals. These results show that filling-in of SFLs is critical in order to effectively use the $\mathrm{O}_{2} \mathrm{~B}$ band for SIF retrievals at a spectral resolution of $0.5 \mathrm{~nm}$.

Line 10 shows results for a simulation with 2 times the nominal noise for the larger B-band fitting window. Precision decreased by approximately a factor of 2 .

\subsection{Sensitivity to spectral resolution, sampling, and wavelength jitter}

We performed simulations for $\mathrm{O}_{2}$-band red SIF retrievals at a resampled higher spectral resolution $(\mathrm{FWHM}=0.3 \mathrm{~nm}$, sampling of $0.1 \mathrm{~nm}$ ) than in the previous simulations. Lines 1112 of Table 1 show retrieval statistics at the higher spectral resolution with the nominal noise model for fitting windows of $682-692 \mathrm{~nm}$ and $682-698 \mathrm{~nm}$, respectively. The precision significantly improves as compared with $\mathrm{FWHM}=0.5 \mathrm{~nm}$ retrievals. This improvement results from (1) more spectral samples within the fitting window and (2) a larger filling-in signal from SIF in the deepest part of the $\mathrm{O}_{2} \mathrm{~B}$ band as well as within the SFLs. This is consistent with the simulations of expected FLEX performance for the red SIF (Cogliati et al., 2015).

We also performed simulations for SFL red SIF retrievals using a single small spectral fitting window that contains only SFLs, similar to that used by Guanter et al. (2015) (682$686.5 \mathrm{~nm}$, lines 13-16 of Table 1). Here we used the nominal noise model with FWHMs of $0.1,0.2,0.3$, and $0.5 \mathrm{~nm}$ with sampling rates of $0.03,0.075,0.1$, and $0.2 \mathrm{~nm}$, respectively. When using only SFLs for the retrieval, a significant improvement is obtained at higher spectral resolutions for the same reasons given above for the $\mathrm{O}_{2}$-band retrievals. Note that good performance can be achieved with a smaller number of PCs for this limited fitting window. The results obtained at FWHM values of 0.5 and $0.3 \mathrm{~nm}$ show that significant improvements are achieved when instrumental noise is simulated and the oxygen B band and $\gamma$ band are included in the spectral fitting as compared with the use of the more limited fitting window that contains only SFLs.

We performed an additional experiment at $0.3 \mathrm{~nm}$ spectral resolution in which we resampled the spectra at the same spacing as used for $0.5 \mathrm{~nm}$ spectral resolution (sampling rate of $0.2 \mathrm{~nm}$ ). As expected, owing to enhanced sensitivity, improvement is obtained at the higher spectral resolution with identical spectral sampling (line 17 of Table 1). This demonstrates the benefits of higher spectral resolution.

Additionally, we simulated a random wavelength jitter with a normal distribution and standard deviation of $0.01 \mathrm{~nm}$ in both training and testing data sets at 0.3 and $0.5 \mathrm{~nm}$ spectral resolutions. Such a jitter may be expected due to changes in the instrument response function with inhomogeneous scenes (e.g., partial clouds). While there is a small degradation in the results, overall the impact of such jitter with our approach is relatively small (lines 18-19 of Table 1 compared with lines 15-16). The effects of the wavelength jitter should be at least partially accounted for by the use of principal components.

Finally, in line 20 we used the same fitting window in our simulations as that used by Wolanin et al. (2015) for SCIAMACHY and GOME-2 retrievals $(681.8-685.5 \mathrm{~nm})$; this is a bit more narrow than that used in lines 13-19. Results should be compared directly with line 16 that uses our fitting window that is $0.8 \mathrm{~nm}$ wider. While bias is reduced by about $0.07 \mathrm{~mW} \mathrm{~m}^{-2} \mathrm{~nm}^{-1} \mathrm{sr}^{-1}$ and the correlation increased from 0.51 to 0.59 with the smaller fitting window, the standard deviation and root-mean-square (RMS) error both increased by more than $0.3 \mathrm{~mW} \mathrm{~m}^{-2} \mathrm{~nm}^{-1} \mathrm{sr}^{-1}$.

\subsection{Radiance residuals from simulated data}

Figure 4 shows the RMS of the radiance residuals (observed minus calculated radiance) for an instrument with FWHM $=0.5 \mathrm{~nm}$, with nominal noise, and for $\mathrm{O}_{2}$-band retrievals using the B-band fitting window of $682-698 \mathrm{~nm}$ when red SIF is versus is not retrieved. The displayed val- 

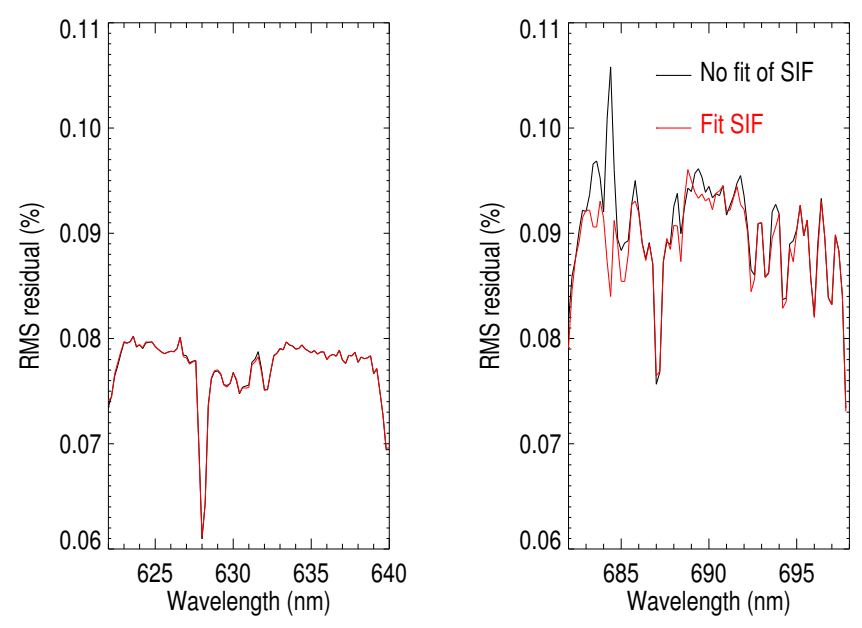

Figure 4. Root mean square (RMS) of simulated radiance residuals (observed minus computed, in \% of radiance) at wavelengths in and around the $\mathrm{O}_{2} \gamma$ band (left) and B band (right) from the testing data set with $\mathrm{FWHM}=0.5 \mathrm{~nm}$ and nominal noise model when fluorescence (SIF) is fit/retrieved (red) and when it is not (black).

ues represent the RMS of the residual at each wavelength averaged over all conditions in the simulation testing data as a percentage of the observed radiance. Reductions in the residuals are shown on average when fluorescence is retrieved, as expected. The RMS reductions are not apparent within the $\mathrm{O}_{2} \gamma$ band portion of the fitting window where fluorescence is not present. Reductions are shown in the $\mathrm{O}_{2}$ B-band portion of the fitting window, both inside and outside the band. Residuals are substantially reduced outside the B band $(\lambda<686.5 \mathrm{~nm})$ where SFL filling from SIF occurs. Smaller, more subtle RMS reductions also occur inside the $\mathrm{O}_{2} \mathrm{~B}$ band, particularly at wavelengths between 687 and $693 \mathrm{~nm}$. When SIF is fitted, the radiance residuals are relatively constant with wavelength at a level of around $0.1 \%$ or less, consistent with the noise levels in the simulation.

\subsection{Discussion of simulation results}

Figure 5 shows results for $\mathrm{O}_{2}$-band (smaller fitting window) and SFL retrievals with $\mathrm{FWHM}=0.5 \mathrm{~nm}$ and nominal noise. This figure shows that negative biases are more prevalent for the $\mathrm{O}_{2}$-band retrievals for certain simulation configurations. However, the improvement in terms of precision obtained with the $\mathrm{O}_{2}$-band retrievals as compared with the SFL approach is also apparent.

Our retrieval approach relies on several simplifying assumptions, such as that the geometrical air mass factor is an appropriate approximation and that the spectral structures of SIF and $\rho_{\mathrm{S}}$ can be modeled reasonably well with a few parameters. The simulated data do not contain these assumptions; the radiances are generated monochromatically with atmospheric scattering before being convolved with the instrument response function, and the spectral dependences of
SIF and $\rho_{\mathrm{S}}$ are based on model and spectral libraries. Therefore, our simulation results should accurately reflect errors produced by our assumptions. As can be seen, the biases and errors produced by these simplifications are relatively small. Our simulation results provide confidence that our method can be used to successfully retrieve red SIF with satellite measurements from GOME-2 and SCIAMACHY provided that the instruments are performing in a linear and expected manner and that remaining biases can be effectively removed.

\section{Results from GOME-2 and SCIAMACHY data}

For GOME-2 and SCIAMACHY $\mathrm{O}_{2}$ red SIF retrievals, we use a fitting window of $682-692 \mathrm{~nm}$ and 15 PCs. Although we obtain good results using simulated data that include wavelengths impacted by $\mathrm{H}_{2} \mathrm{O}$ (vapor) absorption $(692<$ $\lambda<713 \mathrm{~nm}$ ), we found unrealistic month-to-month variations in both far-red and red SIF magnitudes with real satellite data when using wavelengths impacted by $\mathrm{H}_{2} \mathrm{O}$ absorption. These unphysical variations were drastically reduced when we restricted the retrievals to wavelengths with minimal $\mathrm{H}_{2} \mathrm{O}$ absorption. Use of the $682-692 \mathrm{~nm}$ window was chosen to maximize wavelength range in order to minimize the impact of instrumental random noise while minimizing the impact of $\mathrm{H}_{2} \mathrm{O}$ absorption. Similarly, in version 26 of farred GOME-2 SIF retrievals we restricted the fitting window to $734-758 \mathrm{~nm}$, a reduction as compared with that used in Joiner et al. (2013). This also reduced unrealistic month-tomonth variations that were present in earlier versions. For SFL red SIF retrievals, we use a window of $682-686.5 \mathrm{~nm}$ with three PCs. This is slightly larger than the fitting window used by Wolanin et al. (2015) (681.8-685.5 nm).

\subsection{Radiance residuals from GOME-2 for terrestrial retrievals}

Figure 6 shows a sample spectral fit for an observation over the southeastern USA. Improvements in the fit are visible only when the spectral range is reduced to limit the $y$ axis range. The reflectance residuals show that reductions over the entire spectral range are subtle due to the small values of red SIF; the overall reduction in the RMS of the residuals is approximately $7 \%$. A relatively high SNR is necessary to retrieve the small red SIF signal.

Figure 7 is similar to Fig. 4 but shows the spectral RMS of GOME-2 radiance residuals, obtained with and without fitting SIF. The residuals shown here were obtained on a single day (1 July 2007) and are averaged for each wavelength over all observations with $\mathrm{SZA}<70^{\circ}$ and the reflectance-based Normalized Difference Vegetation Index $(\mathrm{NDVI})>0.5$ (i.e., moderately to highly vegetated green pixels) that passed quality control and cloud filtering checks. Reductions in the residuals are modest and of roughly similar magnitude to 

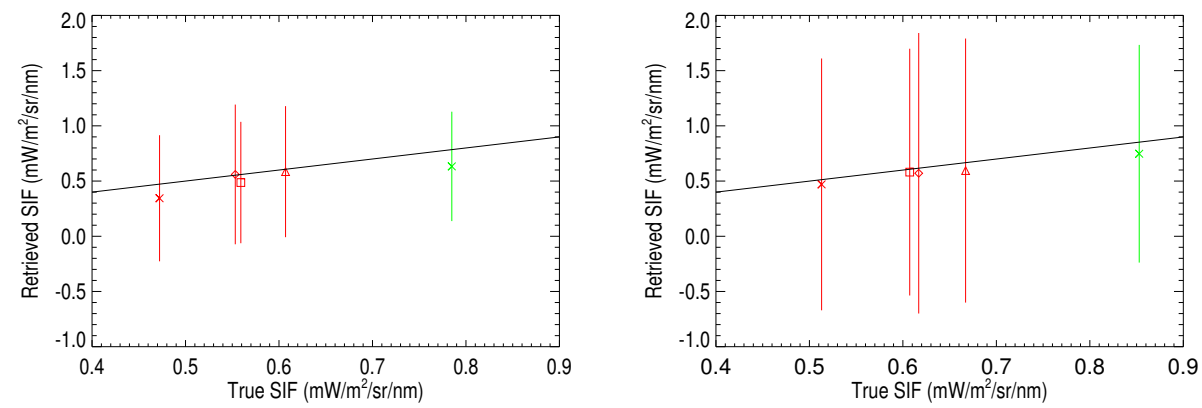

Figure 5. Fluorescence retrievals from simulated data ( $y$ axis) using wavelengths between 682 and 692 nm along with wavelengths surrounding the $\mathrm{O}_{2} \gamma$ band (left) and using wavelengths between 682 and $686.5 \mathrm{~nm}$ (right) for an instrument with FWHM=0.5 nm and with the nominal noise model. Fluorescence is averaged over the fitting window used in the retrieval (different for left and right panels) and compared with the "truth" ( $x$ axis) averaged in the same way. Standard deviations are shown with vertical bars. Different symbols are shown for the various values of chlorophyll content $\left(5,10,20,40 \mu \mathrm{g} \mathrm{cm}^{-2}\right)$ and different colors are for the different values of leaf area index $(0.5,1)$.
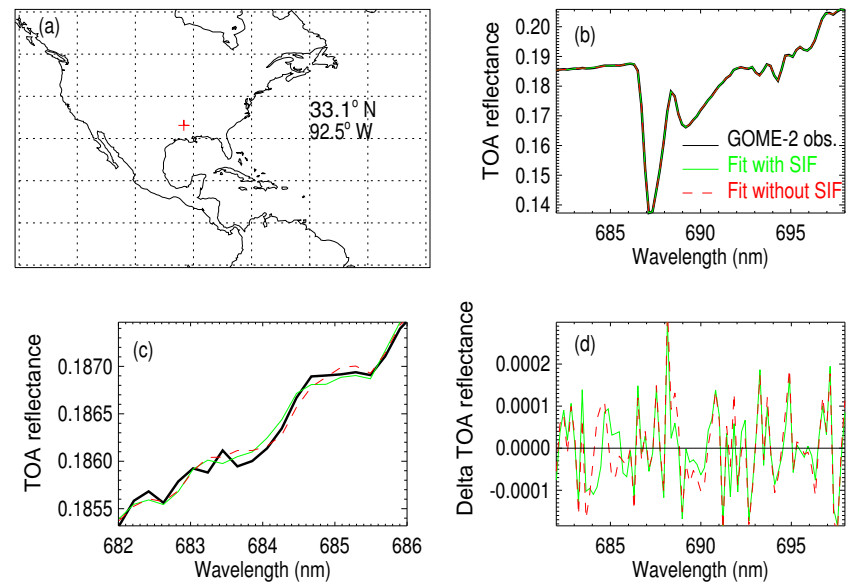

Figure 6. A sample GOME-2 observation made on 1 July 2012 at location specified in (a); observation and spectral fits of top-ofatmosphere (TOA) reflectance with and without SIF for the $\mathrm{O}_{2}$ band retrieval in (b) and (c). (c) is a spectral zoom of (b), and residual of the reflectance spectral fit in (d). The retrieved SIF at reference wavelength $682 \mathrm{~nm}$ was $2.25 \mathrm{~mW} \mathrm{~m}^{-2} \mathrm{~nm}^{-1} \mathrm{sr}^{-1}$. RMS of the residual spectrum is $9.35 \times 10^{-5}$ when SIF is fit and $1.01 \times 10^{-4}$ when SIF is not fit.

those obtained using the simulated data in Fig. 4. RMS residuals are reduced on average $1 \%$ in the wavelength range 682-692 nm for the GOME-2 data used here and about $2 \%$ in the simulated data set. The largest reductions are in the SFLs near $684 \mathrm{~nm}$ and within the deepest part of $\mathrm{O}_{2} \mathrm{~B}$ band around 687-690 nm. Overall, RMS residuals have similar or slightly smaller magnitudes as compared with those shown in Fig. 4 for simulated data. This indicates that the noise model used in our simulations is appropriate for GOME-2. We note somewhat better performance of GOME-2 in the $\mathrm{O}_{2} \gamma$-band spectral region as compared with that near the $\mathrm{B}$ band.
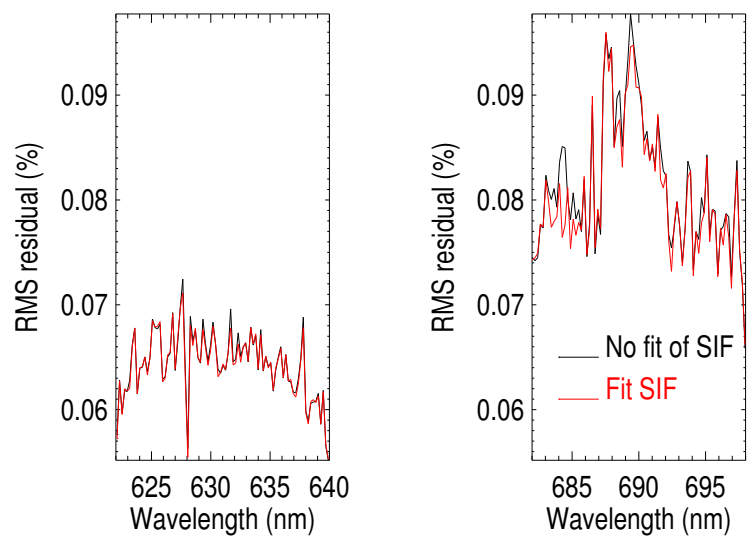

Figure 7. Similar to Fig. 4 for actual GOME-2 radiance residuals (RMS) for pixels with moderate to high amounts of green vegetation (NDVI > 0.5) for a single day (1 July 2007).

\subsection{Comparison of GOME-2 and SCIAMACHY terrestrial red SIF}

Global composites of red SIF derived from SCIAMACHY and GOME-2 for July and December 2009 are displayed in Fig. 8. For comparison, these are the same months displayed in Wolanin et al. (2015). Quality-filtered retrievals have been averaged in $1^{\circ}$ latitude-longitude grid boxes in all cases. The filtering uses data only for $\mathrm{SZA}<70^{\circ}$, where RRS effects should be relatively small (Joiner et al., 2012). A zero-level adjustment is made as described above for all cases. No other explicit account of RRS is made.

The top panels show retrievals obtained using the SFL approach with a fitting window of $682-686.5 \mathrm{~nm}$ for SCIAMACHY. The fitting window is similar to that used by Wolanin et al. (2015). The main difference of our approach as compared with that used by Wolanin et al. (2015) here is that we use the PCA approach to account for $\mathrm{H}_{2} \mathrm{O}$ absorption and our zero-level offset adjustment may account for the effects 

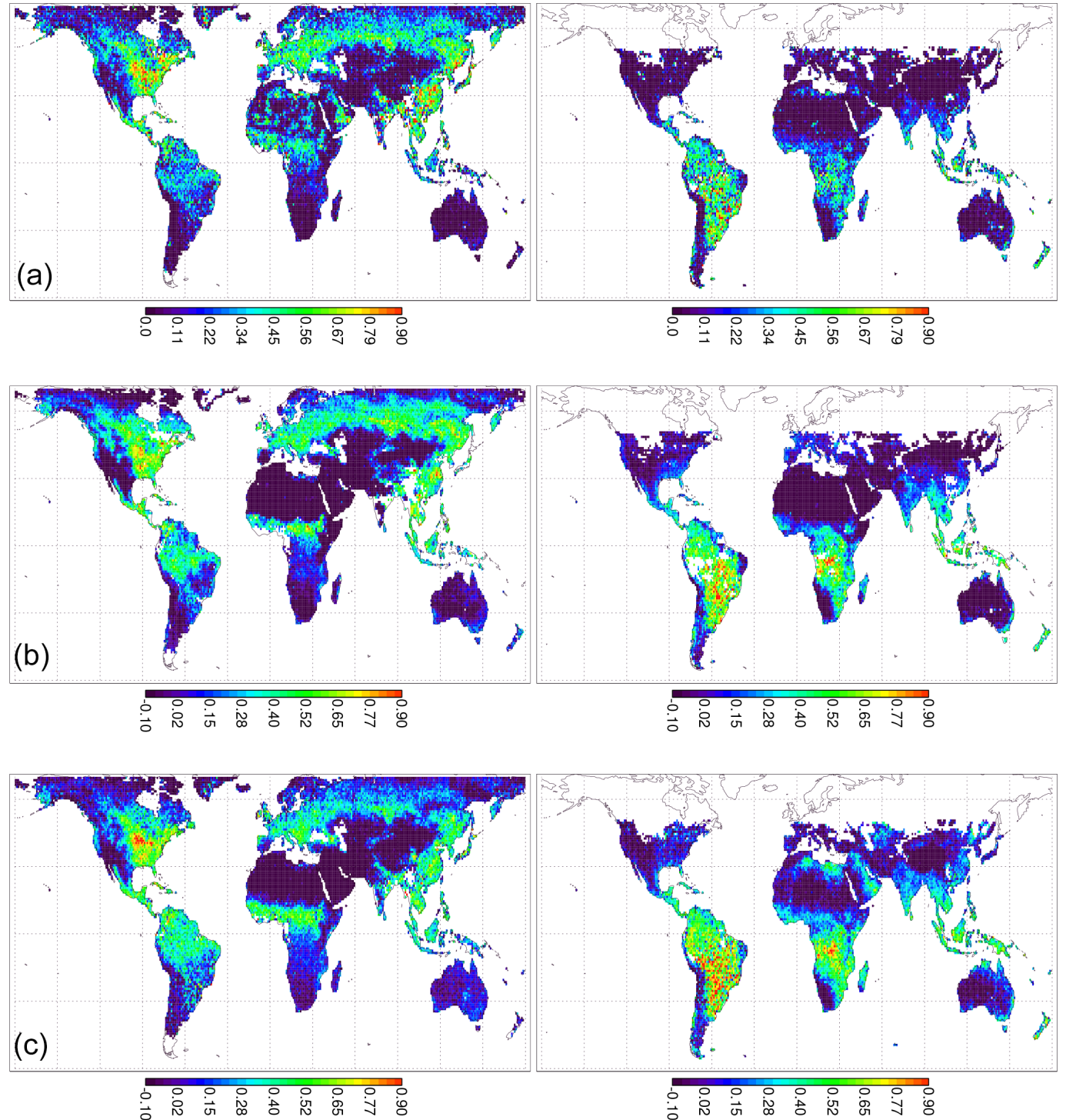

Figure 8. Global composites of red SIF from SCIAMACHY and GOME-2 binned in $1^{\circ}$ cell boxes with zero-level adjustment.(a) SCIAMACHY solar Fraunhofer line (SFL) red SIF retrievals in $\mathrm{mW} \mathrm{m}^{-2} \mathrm{~nm}^{-1} \mathrm{sr}^{-1}$ using fitting window $682-686.5 \mathrm{~nm}$ for July (left) and December (right) 2009. (b) Similar to (a) for SCIAMACHY but using fitting windows in $\mathrm{O}_{2} \gamma(622-640 \mathrm{~nm})$ and B (682-692 nm) bands. (c) Similar to (b) but using GOME-2 (622-640 and 682-692 nm).

of RRS as well as other instrumental artifacts. Magnitudes are similar but perhaps slightly higher than those shown in Wolanin et al. (2015). Here, we display results over all land areas that meet our filtering criteria. Note that retrievals in many areas such as deserts and the Himalayan plateau were not shown in Wolanin et al. (2015), so we are unable to compare results there.

Unrealistically high biases are seen over the Sahara and Arabian peninsula in July and to a lesser extent in December. These are cases of high surface reflectance and small amounts of vegetation. A simple filter for high reflectivities $(>0.35)$ can remove these cases or alternatively they could be used in the training data set for the zero-level offset ad- justment scheme. However, to examine potential instrumental effects and our ability to remove them, we have not filtered the data or included them in the zero-level offset regression training. Similar biases in SCIAMACHY data at the deep Ca II line at $866 \mathrm{~nm}$ were also discussed in Joiner et al. (2012). Zero-level adjustments are typically of the order of a few tenths of a mW m${ }^{-2} \mathrm{~nm}^{-1} \mathrm{sr}^{-1}$. The adjustments do not completely remove biases at high radiance levels as shown here.

The middle and bottom panels show red SIF retrievals obtained using the $\mathrm{O}_{2}$-band retrievals with SCIAMACHY and GOME-2, respectively. A generally good agreement of the SIF magnitudes and spatial patterns is observed between the 

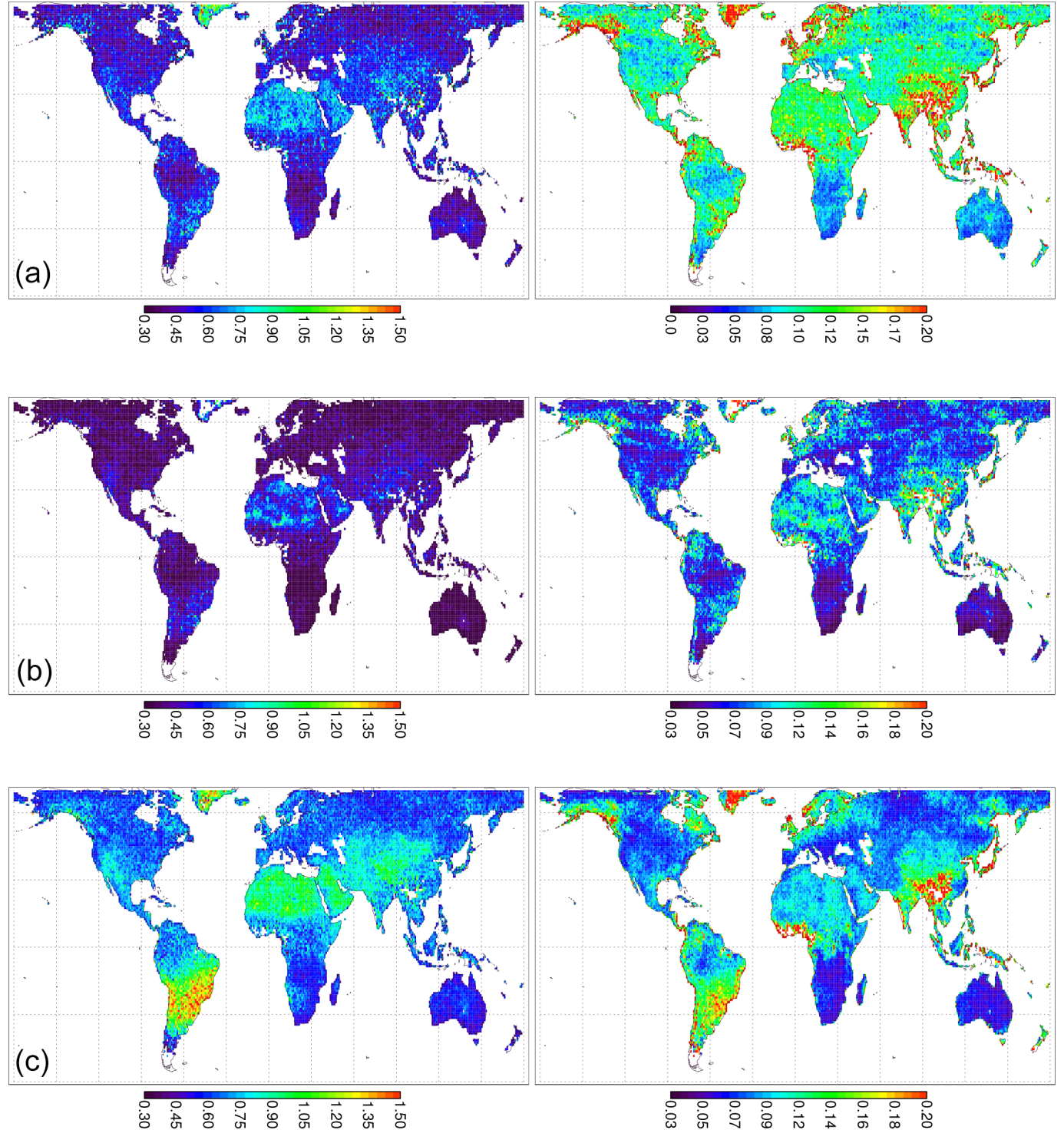

Figure 9. Global maps of red SIF retrieval statistical parameters in $1^{\circ}$ grid cells for July 2007. (a) Grid cell standard deviation (left) and standard error (right) for SCIAMACHY SFL red SIF retrievals in $\mathrm{mW} \mathrm{m}^{-2} \mathrm{~nm}^{-1} \mathrm{sr}^{-1}$ (682-686.5 nm). (b) Similar to (a) but for SCIAMACHY O 2 -band red SIF retrievals (622-640 and 682-692 nm). (c) Similar to (b) but for GOME-2 red SIF retrievals using 622-640 and $682-692 \mathrm{~nm}$.

satellite retrievals obtained with different instruments and fitting windows. Relatively higher red SIF values are observed over vegetated areas, while low (or sometimes negative) values are obtained over deserts and sparsely vegetated areas. Spatial patterns of active regions are similar to those of farred SIF retrievals $(734-770 \mathrm{~nm})$ obtained by GOME-2 and GOSAT. Values of red SIF are generally lower than those obtained in the far red consistent with previous canopy-level ground-based measurements (Daumard et al., 2010; Cheng et al., 2013; Fournier et al., 2012).

Positive biases over bright desert areas are less prevalent in the $\mathrm{O}_{2}$-band retrievals, particularly for SCIAMACHY. However, some biases are seen in the GOME-2 retrievals in De- cember. Again, these can be removed with a simple high reflectance filter. We also note that there are larger negative biases over non-vegetated areas obtained with SCIAMACHY as compared with GOME-2. The fact that similar results are obtained over vegetated areas suggests that the instruments are behaving differently over high reflectivity scenes. There are other differences between the retrievals even in vegetated areas. In the case where identical algorithms are applied, these differences are likely instrument related and will be explored in more detail below.

We note that biases (both before and after zero-level adjustment) vary over time. Figure S9 shows similar results obtained in 2007. The unphysical high biases over the Sa- 

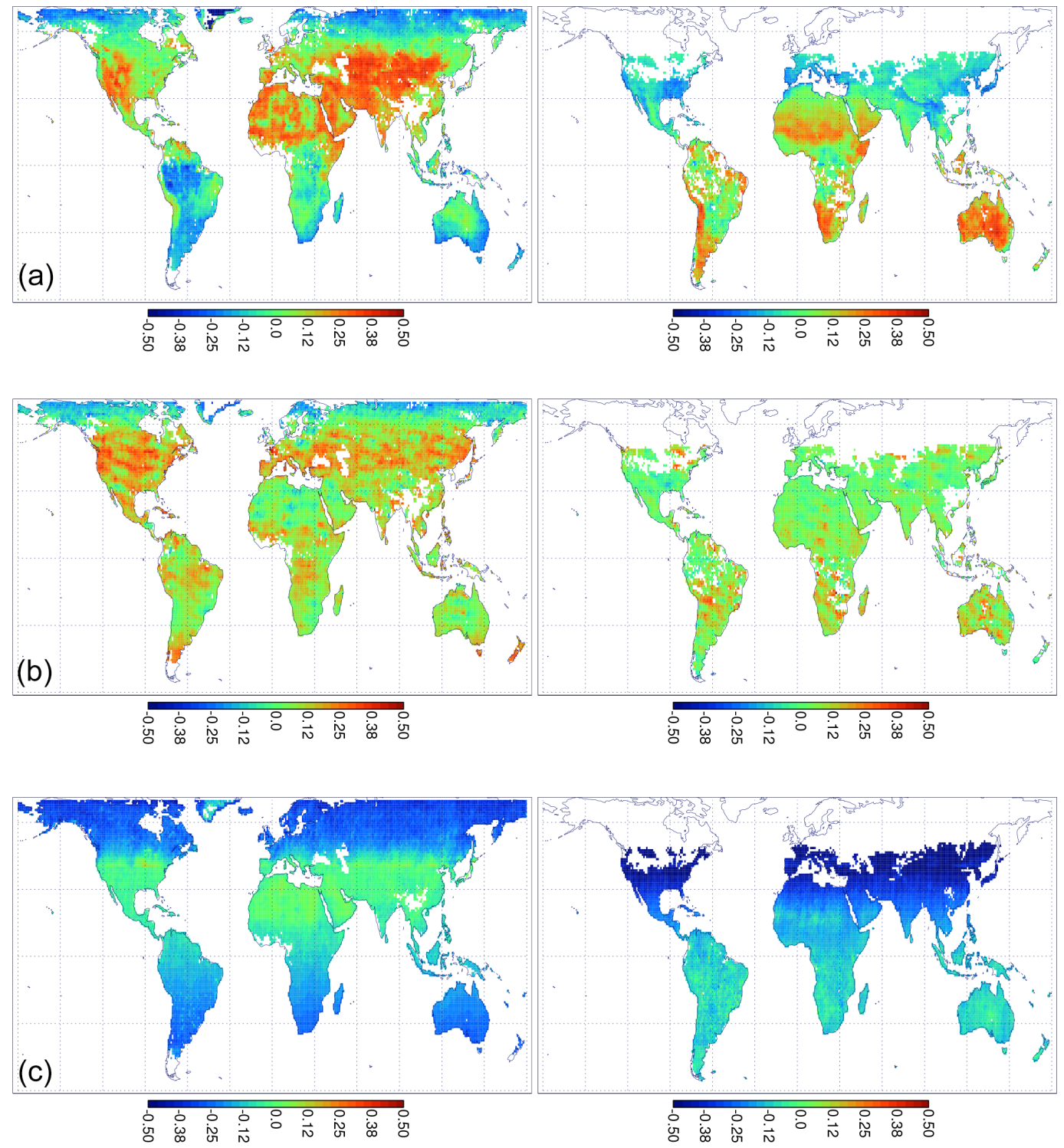

Figure 10. Global maps of the zero-level adjustment July (left) and December (right) 2007. (a) Zero-level adjustment for July (left) and December (right) 2007 for SCIAMACHY SFL red SIF retrievals in $\mathrm{mW} \mathrm{m}^{-2} \mathrm{~nm}^{-1} \mathrm{sr}^{-1}$ (682-686.5 nm). (b) Similar to (a) but for SCIAMACHY O 2 -band red SIF retrievals (622-640 and 682-692 nm). (c) Similar to (b) but for GOME-2 retrievals (622-640 and 682-692 nm).

hara are much reduced for the SFL retrievals in July 2007 as compared with July 2009 and similarly for the GOME-2 $\mathrm{O}_{2}$ band retrievals in December 2007 as compared with 2009. It should be noted again that these red SIF retrievals are derived using instruments that were not designed or optimized for such measurements.

\subsection{Variability, biases, and estimated errors in GOME-2 and SCIAMACHY terrestrial red SIF retrievals}

Standard deviations of the July 2007 red SIF retrievals in the left panels of Fig. 9 show the variability of the retrieved red
SIF in $1^{\circ} \times 1^{\circ}$ grid boxes for the three different retrievals in Fig. 8. SCIAMACHY retrievals show less variability in general as compared with GOME-2, particularly in the area impacted by the SAA (high variability over parts of South America). This indicates a better performance per pixel of the SCIAMACHY instrument in the red spectral region. Lower variability is shown for the SCIAMACHY $\mathrm{O}_{2}$ retrievals than the SFL retrievals as may be expected from the use of a larger spectral range. Additional variability affecting all retrievals results from natural variability in vegetation activity within the month, the effects of different illumination and viewing geometries, and the different footprints from the satellite orbits. Clouds and aerosols can affect both types of retrievals 
(a)

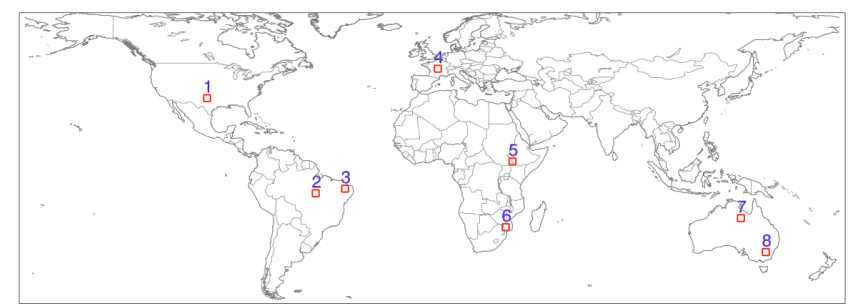

(b)
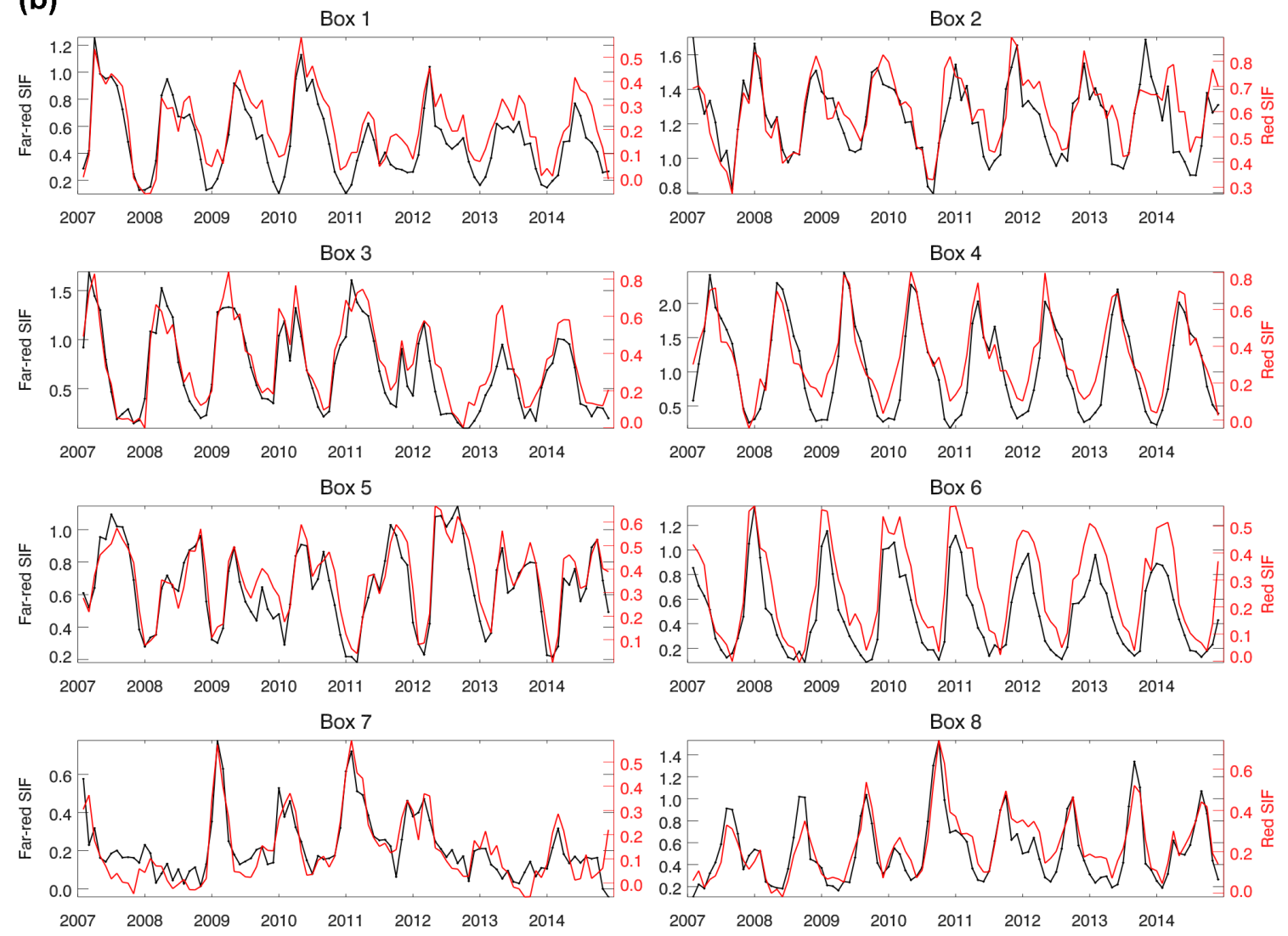

Figure 11. (a) Map showing boxes where SIF time series will be examined. (b) Time series of monthly red (red, right axes) and far-red SIF (black, left axes) in $\mathrm{mW} \mathrm{m} \mathrm{nm}^{-1} \mathrm{sr}^{-1}$ from GOME-2 for eight boxes shown in (a).

by a blocking effect but can additionally affect $\mathrm{O}_{2}$ retrievals by altering the depth of the $\mathrm{O}_{2}$ absorption features. There does not appear to be additional noise resulting from these cloud effects on the $\mathrm{O}_{2}$ retrievals.

In general for both instruments, higher standard deviations occur over brighter scenes (e.g., over Greenland and deserts), consistent with the higher noise expected at higher radiance levels. Interestingly, vegetation patterns are not obvious in the standard deviation maps, indicating that there is not much additional variability contributed by vegetation as compared with that from instrumental noise. This was not the case for far-red retrievals from GOME-2 and SCIAMACHY (Joiner et al., 2013; Köhler et al., 2015). Variability due to noise (in radiance units) in sparsely vegetated areas is higher for GOME- 2 in the red as compared with the far red shown in
Joiner et al. (2013). Variability in vegetated areas is similar for both red and far-red SIF.

The right panels of Fig. 9 show computed standard errors of the monthly mean (grid box standard deviations divided by the square root of the number of retrievals). Despite lower variability in the SCIAMACHY SFL red SIF retrievals, the GOME-2 retrievals show lower standard errors than SCIAMACHY SFL retrievals in all but a few areas due to more observations per month. The SCIAMACHY $\mathrm{O}_{2}$-band red SIF retrievals provide slightly lower standard errors in most areas as compared with those of GOME-2. However, there is some block-like structure in the SCIAMACHY standard errors. The block-like structure results from alternating blocks of nadir and limb retrievals that were performed by SCIAMACHY. GOME-2 operates exclusively in the nadir mode, which leads to a better spatial coverage. 

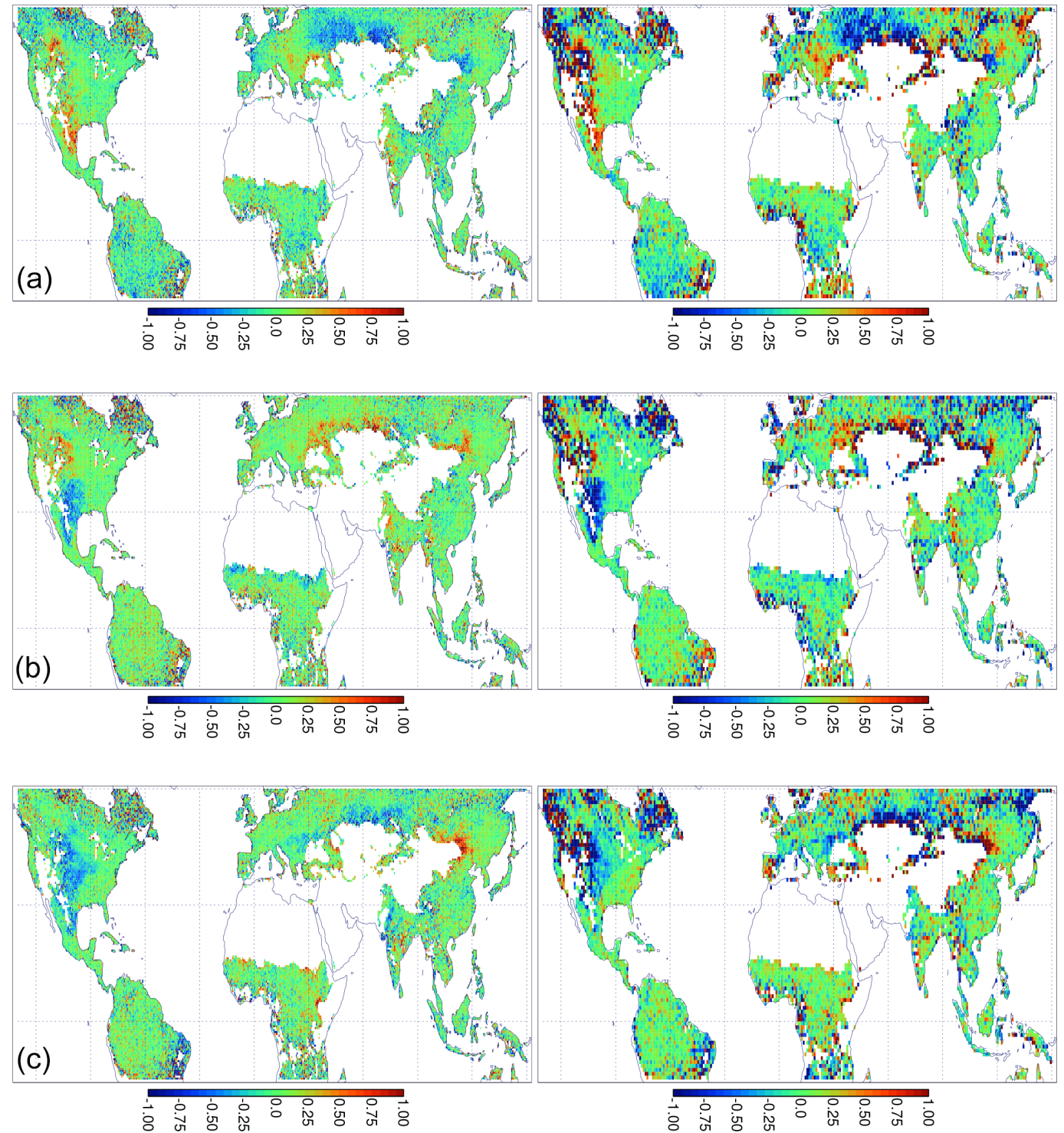

Figure 12. Global SIF anomaly maps (in terms of fractional differences from monthly climatological values computed as averages over the years 2007-2014) for August 2010, 2011, and 2012 (top to bottom) for GOME-2 far-red (left) and red (right) retrievals. (a) SIF anomalies (monthly mean subtracted from observed value at each grid box and then divided by the mean value to provide an anomaly in terms of fractional amount of a climatological value) for August 2010 for far-red (left) and red (right) GOME2 SIF retrievals. (b) Similar to (a) but for August 2011. (c) Similar to (b) but for August 2012.

Figure 10 shows monthly mean zero-level offset adjustments for July and December 2007 for the three red SIF retrievals. Both SCIAMACHY retrievals show positive and negative adjustments, while GOME- 2 shows mostly negative adjustments. SCIAMACHY adjustments for the $\mathrm{O}_{2}$-band red SIF retrievals show alternating blocky spatial patterns; this results from day-to-day variation in the estimated zerolevel adjustments. Adjustments for the two SCIAMACHY retrievals vary because they are using different retrieval approaches and fitting windows. The $\mathrm{O}_{2} \mathrm{~B}$ band is a deeper feature than the SFLs and may therefore behave differently.
RRS increases rapidly with SZA at high SZAs (Joiner et al., 2012). The zero-level adjustments do not clearly or consistently show this effect.

As can be seen, the zero-level adjustments are substantial in many areas. Uncertainties in the zero-level adjustment likely dominate the retrieval errors. The day-to-day and even at times orbit-to-orbit variation in the SCIAMACHY offsets lead to larger uncertainties than for GOME-2. Note that there are some discontinuities at the latitudes where the boundaries for the adjustments are defined. However, they are not very pronounced in the figures. Based on the magni- 

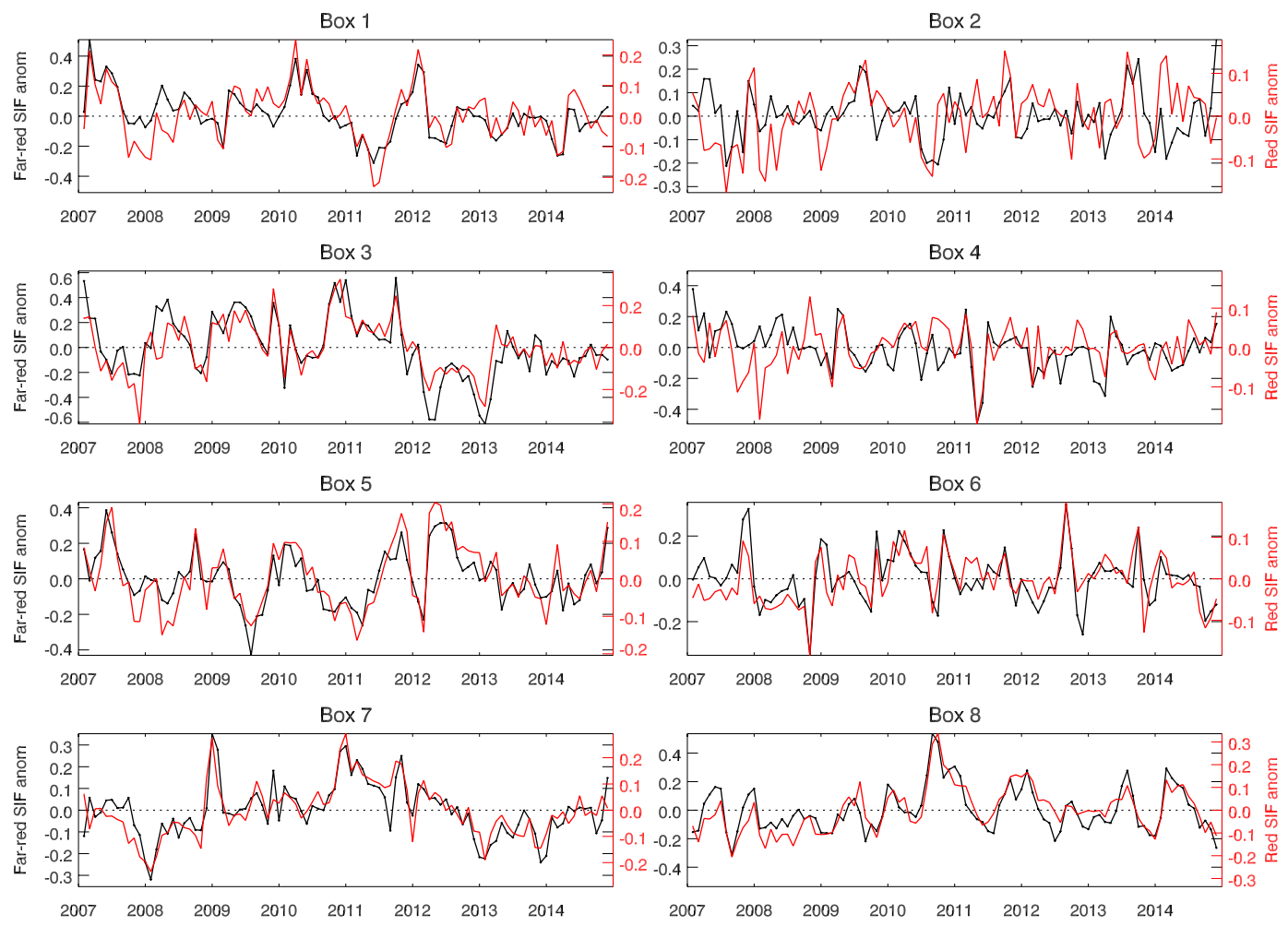

Figure 13. Similar to Fig. $11 \mathrm{~b}$ but showing time series of red and far-red SIF monthly anomalies (in $\mathrm{mW} \mathrm{m}^{-2} \mathrm{~nm}^{-1} \mathrm{sr}^{-1}$ ) from GOME-2 for eight boxes shown in Fig. 11a.

tude and stability of the adjustments, we estimate that uncertainties in monthly mean red SIF retrievals are in the range $0.1-0.3 \mathrm{~mW} \mathrm{~m}^{-2} \mathrm{~nm}^{-1} \mathrm{sr}^{-1}$ for SCIAMACHY data and 0.1$0.2 \mathrm{~mW} \mathrm{~m}^{-2} \mathrm{~nm}^{-1} \mathrm{sr}^{-1}$ for GOME- $2 \mathrm{O}_{2}$-band retrievals.

\subsection{Time series and mapped anomalies for terrestrial retrievals}

We display time series of red and far-red SIF from GOME-2 for the boxes shown in Fig. 11a. We focus on GOME-2 so that we may compare the long time series of red SIF with the GOME-2 far-red SIF data set. The boxed areas were selected because they display significant interannual variability (IAV). Each box is an average over an area of $3^{\circ}$ latitude by $3^{\circ}$ longitude. This resolution was selected in order to reduce the effects of instrumental noise to focus on the interannual variations.

Figure $11 \mathrm{~b}$ shows that both red and far-red SIF display similar seasonality. Many of the boxes shown also display a fair amount of IAV. The IAV is similar for red and far-red SIF and in the areas shown is driven primarily by water availability. Yoshida et al. (2015) and Sun et al. (2015) showed that drought-related negative SIF anomalies (e.g., the 2011 low values shown for Box 1 in the Texas drought area) are driven by decreases in the fraction of absorbed photosynthetically active radiation (fPAR) as well as decreases in fluo- rescence efficiency that is related to electron transport rate within leaves. There is a somewhat earlier autumn or dry season decline in the far-red SIF as compared with the red in some of the boxes ( 1 and 2). The seasonality of far-red SIF has been shown to closely match that of GPP derived from flux tower eddy covariance measurements while greenness vegetation indices that are related to fPAR tended to decline later in autumn (Joiner et al., 2014).

To further assess the GOME-2 red SIF data set, we compute monthly mean anomalies and compare them with those from the far red. We should expect to see some similarities in the anomalies, particularly those driven by moisture stress (e.g., Daumard et al., 2010; Ač et al., 2015; Middleton et al., 2015). Showing consistency (or not) in the anomalies demonstrates the ability to resolve small signals and therefore provides a check on the estimated errors and sensitivities.

Figure 12 shows mapped gridded monthly anomalies for far-red and red SIF from GOME-2 for August 2010, 2011, and 2012. These months highlight the impact of droughts where SIF satellite observations have been studied previously (Yoshida et al., 2015; Sun et al., 2015; Lee et al., 2013). To generate the anomalies, monthly mean climatological maps averaged over the years between 2007 and 2014 are subtracted from the monthly means. The anomalies are then shown as a fraction of the climatological grid box value for a particular month. Far-red SIF anomalies are gridded at 

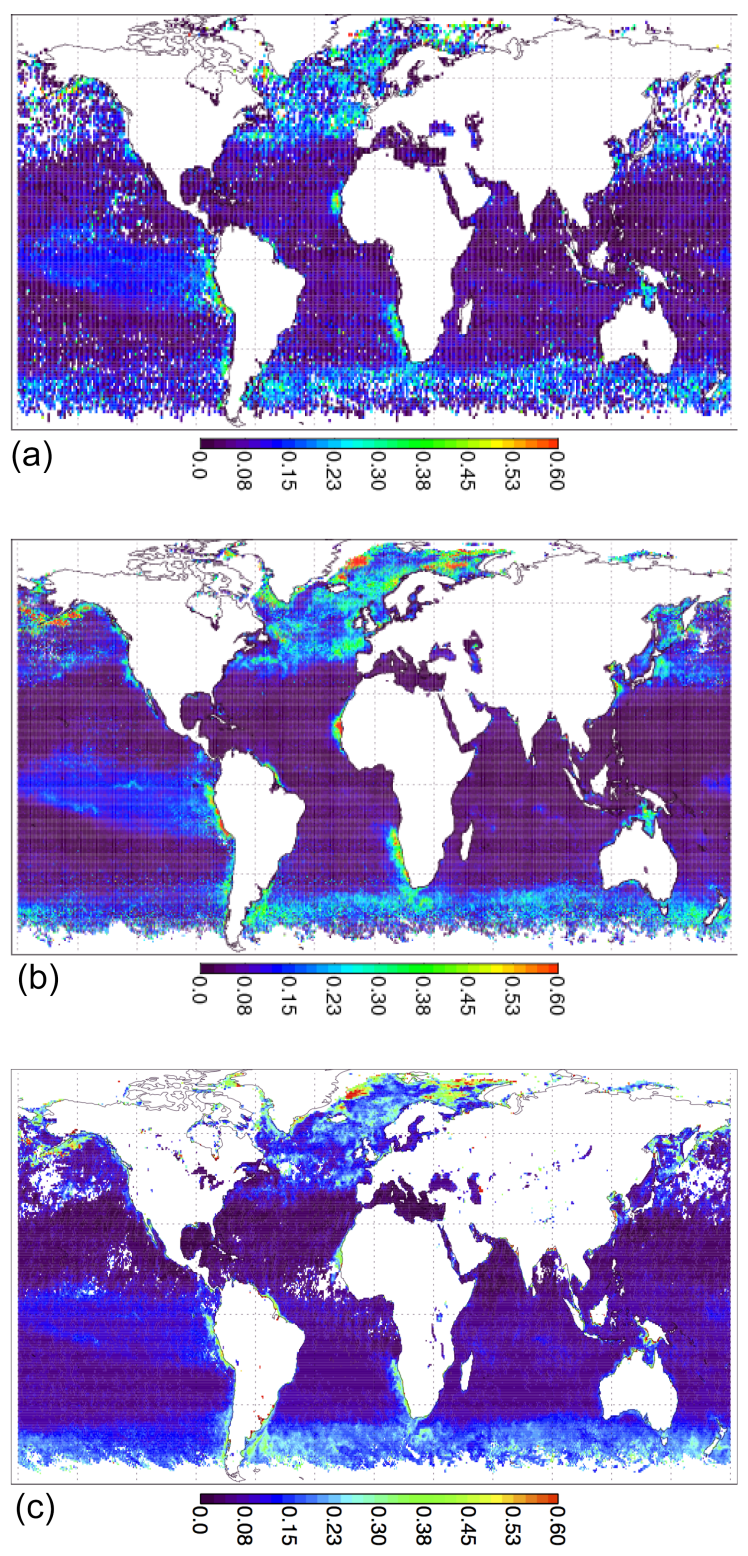

Figure 14. Monthly mean (simplified) normalized fluorescence line height (nFLH) from SCIAMACHY (top), GOME-2 (middle), and Terra MODIS (bottom) in $\mathrm{mW} / \mathrm{m}^{2} / \mathrm{sr} / \mathrm{nm}$ for May 2007. SCIAMACHY and GOME-2 are gridded to spatial resolutions of 0.5 and $1^{\circ}$, respectively. MODIS data were obtained at a $9 \mathrm{~km}$ spatial resolution but regridded to the same resolution as GOME2/SCIAMACHY. No zero-level adjustments are made to the retrievals. (a) SCIAMACHY simplified nFLH as described in text. (b) Similar to (a) but for GOME-2. (c) MODIS nFLH.

a resolution of $0.5^{\circ}$ resolution; this is the standard resolution used for publicly available level 3 gridded data set. To reduce the impact of retrieval noise, red SIF anomalies are shown at a lower resolution of $1^{\circ}$. Data are shown for grid boxes where the climatological NDVI from GOME-2 $>0.2$.
Negative anomalies due to the Russian drought of 2010 are clearly shown in both red and far-red SIF anomaly maps while at the same time positive anomalies are shown in the western USA and northeastern Mexico. Smaller negative anomalies are also shown in southern Amazonia in 2010 and may be the result of the drought conditions (Lewis et al., 2011; Lee et al., 2013). Shown in terms of a percent of the monthly mean climatological values, the anomalies appear to be somewhat larger in the red SIF as compared with the far red. However, the differences may be within the uncertainties of the zero-level adjustment scheme.

Negative SIF anomalies due to the Texas drought of 2011 are also shown in both red and far-red SIF in Texas and northern Mexico, while mostly positive anomalies are shown in the Russian grain belt during this year. Similarly, negative far-red and red SIF anomalies are shown in the region of the 2012 US Great Plains drought in the western USA. Spatial patterns of red and far-red anomalies are consistent elsewhere such as just to the south of the Sahara and to the east of the Gobi desert.

Figure 13 shows time series of monthly anomalies (absolute magnitudes in radiance units, not fractional values) for boxes from Fig. 11a. Overall, the temporal dependence of the anomalies is very similar, at least to within the uncertainties of the measurements. The deseasonalization performed here allows us to demonstrate that the ability of the GOME-2 monthly red SIF at the box resolution to resolve signals is of the order of $\pm 0.1 \mathrm{~mW} \mathrm{~m} \mathrm{~mm}^{-2} \mathrm{nr}^{-1}$. Expected future work includes a closer examination of the anomalies.

\subsection{Oceanic SIF retrievals}

Here, we retrieve oceanic fluorescence line height (FLH) with GOME-2 and SCIAMACHY using the method discussed above. Normalized FLH (nFLH) from SCIAMACHY and GOME-2 is shown in Fig. 14 along with results from the simpler three broadband channel approach applied to the Terra MODIS. Aqua MODIS results, not shown, were similar, but we show Terra data here as the local overpass times are more similar to those of Envisat and MetOp). MODIS data, provided at a spatial resolution of $9 \mathrm{~km}$, were downloaded from http://oceandata.sci.gsfc.nasa.gov.

Here, we apply a very simple adjustment to provide normalized fluorescence line height (nFLH, normalized with respect to incoming solar irradiance) to facilitate comparisons with MODIS nFLH. Our approach accounts only for $\cos \left(\theta_{0}\right)$ (i.e., it does not account for the effects of atmospheric scattering and absorption or changes in the sun-Earth distance). We note that our results are referenced to $683 \mathrm{~nm}$ while MODIS uses slightly different wavelengths, so our magnitudes are expected to be somewhat higher as is generally shown.

Finally, it should be noted that a more liberal cloud filter is applied to the GOME-2 and SCIAMACHY retrievals as compared with that used for MODIS, particularly consider- 

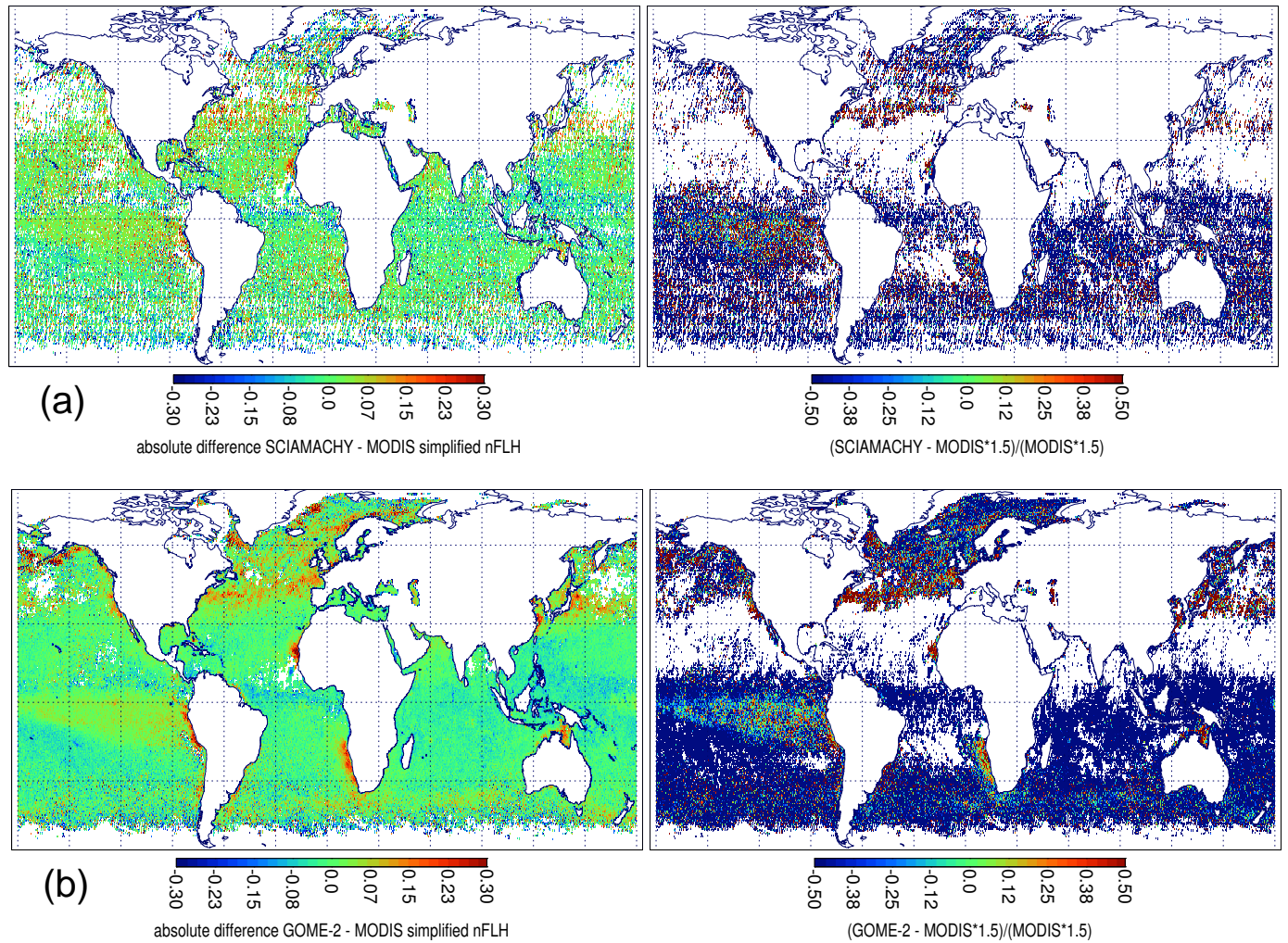

Figure 15. Monthly mean (simplified) normalized fluorescence line height (nFLH) differences between SCIAMACHY and MODIS (a), and GOME-2 and MODIS (b) for May 2007 in terms of absolute difference (left) and fractional difference with respect to MODIS (right) for grid boxes where MODIS nFLH $>0.05$. MODIS values on the right have been scaled up by 1.5 to produce fractional differences near 0 in the Pacific low latitudes in (b) below to show that differences are not a simple scale factor.

ing that MODIS has a much smaller footprint (of the order of $1 \mathrm{~km}^{2}$ ).

The reader is reminded that GOME-2 provides superior surface sampling as compared with SCIAMACHY as it operates in nadir mode exclusively. In Fig. 14 we display GOME2 data gridded at a $0.5^{\circ}$ spatial resolution. SCIAMACHY, which alternated between limb and nadir-mode observations, is gridded at a resolution of $1^{\circ}$ so as not to show too many gaps between grid boxes. MODIS data were regridded to the same resolution as GOME-2. Our monthly means from GOME-2, using the full wavelength range between 660 and $713 \mathrm{~nm}$, appear to be less noisy (patchy) than a GOME-2 yearly mean shown by Wolanin et al. (2015) that was obtained with a smaller fitting window that included only SFLs.

Figure 15 shows maps of absolute and fractional differences in nFLH between SCIAMACHY and MODIS as well as GOME-2 and MODIS. For the fractional difference, we scale MODIS by a factor of 1.5 to show that the difference is not a simple scale factor (this factor brings the differences to near 0 in the Pacific where nFLH values are generally larger than 0). Larger fractional differences are seen in the Northern Hemisphere and off the west coast of Africa. This may be related to the presence of absorbing aerosols that are common in these regions (i.e., smoke, dust, and industrial aerosols) that may affect the MODIS and GOME-2/SCIAMACHY retrievals differently. The spatial patterns of the difference in absolute amount of nFLH with respect to MODIS are similar for GOME-2 and SCIAMACHY. MODIS nFLH is higher than both GOME-2 and SCIAMACHY over large portions of the less productive ocean regions in the Southern Hemisphere. It appears that MODIS has a zero-level offset in the Southern Hemisphere as low values appear to have slightly positive values as compared with the Northern Hemisphere where values are closer to 0. GOME-2 and SCIAMACHY $\mathrm{nFLH}$ values are higher than those from MODIS in the upwelling coastal areas where nFLH has high values.

Figure 16 shows a sample GOME-2 spectrum and fit off the Mexican coast. Improvement in the fit results from fitting the broad spectral feature of SIF emission, particularly at wavelengths $660-685 \mathrm{~nm}$. The overall reduction in RMS of the reflectance residual is about $30 \%$.

Figure 17 shows the mean spectral residuals with and without fitting ocean fluorescence for GOME-2 on 1 July 2007 averaged over all pixels with FLH $>0.4 \mathrm{~mW} \mathrm{~m}^{-2} \mathrm{~nm}^{-1} \mathrm{sr}^{-1}$. The spectral structure of the reduction in residuals further supports the conclusion that most of the information in fit- 

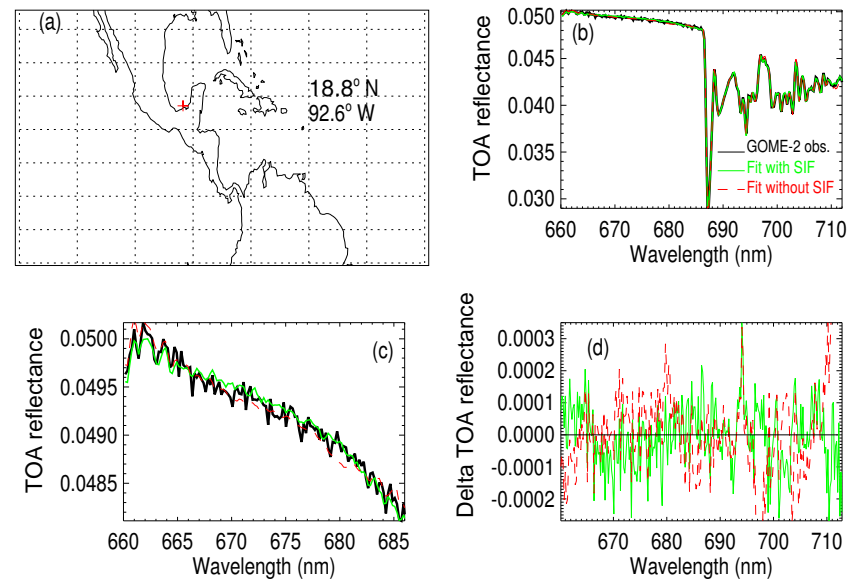

Figure 16. Similar to Fig. 6 but showing a GOME-2 observation on 1 July 2012 and spectral fits for an ocean pixel with retrieved FLH of $0.57 \mathrm{~mW} \mathrm{~m}^{-2} \mathrm{~nm}^{-1} \mathrm{sr}^{-1}$. RMS of the residual spectrum is $1.04 \times 10^{-4}$ when SIF is fit and $1.35 \times 10^{-4}$ when SIF is not fit.

ting for ocean FLH is coming from the broad SIF continuum emission as opposed to filling-in of telluric absorption features or SFLs. We note that some of the remaining fine structure in the residuals may be due to residual filling-in from atmospheric rotational or oceanic VRS or instrumental effects that we did not attempt to account for in this work.

\section{Conclusions}

We have developed new approaches to retrieve SIF at red wavelengths over land from moderate spectral resolution satellite instruments. We also showed for the first time that red SIF can be retrieved over ocean with good fidelity with the same instruments by utilizing the full wavelength range of the SIF emission in this spectral range. Similar to previous works, we use a PCA approach to estimate the spectral structure of atmospheric absorption. Our PCA approach as applied to land retrievals utilizes the $\mathrm{O}_{2} \gamma$ band, which is relatively free of SIF, as well as the filling-in of SFLs to estimate absorption within the $\mathrm{O}_{2} \mathrm{~B}$ band that is used to increase the precision of SIF retrievals. A simplified radiative transfer model based on the geometrical air mass factor approximation is used to determine how much of the emitted surface SIF signal is absorbed in the atmosphere.

We used simulated data computed with a full radiative transfer model for thousands of different scenarios to demonstrate that good-quality red SIF retrievals may be obtained using satellite instrumentation with a relatively high SNR and moderate spectral resolution similar to GOME-2 and SCIAMACHY, provided that unmodelled effects, such as complex instrumental artifacts and Raman scattering, do not severely impact the retrievals. Retrieval errors depend upon the instrument SNR, the spectral fitting window used, and spectral resolution. Our simulations suggest that use of the

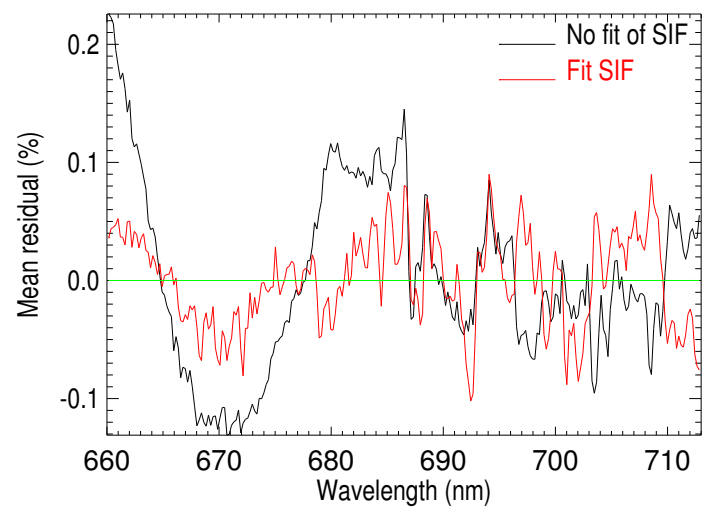

Figure 17. Similar to Fig. 7 but showing the mean of the residuals within the full band algorithm fitting window for ocean pixels with moderate to high amounts of ocean fluorescence (FLH $>0.4 \mathrm{~mW} \mathrm{~m}^{-2} \mathrm{~nm}^{-1} \mathrm{sr}^{-1}$ ) for a single day (1 July 2007).

$\mathrm{O}_{2} \gamma$ and $\mathrm{B}$ bands can increase red SIF retrieval precision over land as compared with approaches that utilize a smaller fitting window confined to regions outside the $\mathrm{O}_{2} \mathrm{~B}$ band where the SIF signal is obtained solely by filling-in of SFLs.

We applied our new approach to satellite measurements from GOME-2 and SCIAMACHY. The GOME-2 and SCIAMACHY retrievals that use the $\mathrm{O}_{2} \gamma$ and $\mathrm{B}$ bands compare well with those from SCIAMACHY that use the less complex and also less sensitive SFL filling narrow window approach. Our long time series of red SIF from GOME-2 allows for the calculation of globally mapped monthly mean anomalies. These first maps of red SIF anomalies show similar temporal and spatial patterns as compared with far-red SIF anomalies with somewhat larger fractional values.

Several satellite instruments with red spectral coverage and various spectral and spatial resolutions have flown, are currently flying, or are planned for launch in the next few years. The approach outlined here can potentially be applied to these instruments. The original GOME instrument, launched in 1995 on the ESA European Remote Sensing satellite 2 (ERS-2), can also be used for red SIF measurements, but with a larger pixel size $(40 \mathrm{~km} \times 320 \mathrm{~km})$ in its nominal operating mode. GOME has the unique ability to extend the record of SIF measurements back to 1995 .

In the future, the approach developed here may be applied to the US National Aeronautics and Space Administration (NASA) Earth Ventures 1 Tropospheric Emissions: Monitoring of Pollution (TEMPO) (Zoogman et al., 2016), a geostationary instrument designed primarily for air quality measurements planned for launched near the end of the decade. TEMPO should provide the first hourly terrestrial red SIF measurements throughout the day with coverage over much of the populated areas of North America as well as hourly oceanic SIF over surrounding coastlines. With nearly continuous spectral coverage from the UV through approximately $740 \mathrm{~nm}$ and a spectral resolution of 
$\sim 0.6 \mathrm{~nm}$, it should obtain time-resolved far-red as well as red SIF retrievals at a substantially higher spatial resolution (native ground pixel of $2 \mathrm{~km}$ by $4.5 \mathrm{~km}$ at the center of the field of regard) than GOME-2 or SCIAMACHY. As mentioned above, TROPOMI will have the capability to measure both red and far-red SIF. It will be in an early afternoon orbit and will have a ground resolution of $\sim 7 \times 7 \mathrm{~km}^{2}$ (Guanter et al., 2015). FLEX (Drusch et al., 2016), a selected ESA Earth Explorer 8 mission, plans to utilize the $\mathrm{O}_{2}$ A and B bands as well as available SFLs for SIF retrievals (Guanter et al., 2010; Cogliati et al., 2015) and other bio-spectral information across the visible/NIR spectrum including the full chlorophyll fluorescence spectrum (650$780 \mathrm{~nm})$. FLEX will provide measurements at an even higher spatial resolution $(\sim 300 \mathrm{~m})$ at approximately a monthly timescale.

\section{Data availability}

GOME-2 far-red SIF level 3 data sets are publicly available from http://avdc.gsfc.nasa.gov/index.php?site= $1353468771 \& \mathrm{id}=75 \& \mathrm{go}=$ list\&path=/MetOp-A/level3

(Joiner et al., 2013). GOME-2 red SIF level 3 data sets are publicly available at http://avdc.gsfc.nasa.gov/index.php? site $=1353468771 \&$ id $=75 \&$ go=list $\&$ path=/MetOp-A_Red/ level3.

\section{The Supplement related to this article is available online at doi:10.5194/amt-9-3939-2016-supplement.}

Acknowledgements. Funding for this work was provided by NASA and the Emmy Noether Programme (GlobFluo project) of the German Research Foundation. The authors are indebted to Phil Durbin, Ghassan Taha, and Michael Yan for their assistance with the satellite data sets. We gratefully acknowledge the European Meteorological Satellite (EUMETSAT) program, ESA, and NASA, particularly the MODIS data processing team, for making available the GOME-2, SCIAMACHY, and MODIS data used here. We also thank Alexander Vasilkov, Karl (Fred) Huemmrich, William Cook, Qingyuan Zhang, Rose Munro, Rüdiger Lang, Joseph Berry, John Burrows, P. K. Bhartia, Petya Campbell, Lawrence Corp, Kelly Chance, and Arlindo da Silva for helpful discussions. Finally, we thank the two anonymous reviewers for comments and suggestions that helped to improve the manuscript.

Edited by: M. Weber

Reviewed by: two anonymous referees

\section{References}

Abbott, M. R., and Letelier, R. M.: Algorithm theoretical basis document chlorophyll fluorescence, available at: http://www.modis. gsfc.nasa.gov/data/atbd (last access: 1 November 2015), 1999.

Ač, A., Malenovský, Z., Olejníčková, J., Gallé, A., Rascher, U., and Mohammed, G.: Meta-analysis assessing potential of steadystate chlorophyll fluorescence for remote sensing detection of plant water, temperature and nitrogen stress, Rem. Sens. Environ., 168, 420-436, doi:10.1016/j.rse.2015.07.022, 2015.

Agati, G., Mazzinghi, P., Fusi, F., and Ambrosini, I.: The f685/f730 chlorophyll fluorescence ratio as a tool in plant physiology - response to physiological and environmental-factors, J. Plant Physiol., 145, 228-238, 1995.

Agati, G., Mazzinghi, P., diPaola, M. L., Fusi, F., and Cecchi, G.: The F685/F730 chlorophyll fluorescence ratio as indicator of chilling stress in plants, J. Plant Physiol., 148, 384-390, 1996.

Agati, G., Cerovic, Z. G., and Moya, I.: The effect of decreasing temperature up to chilling values on the in vivo f685/f735 chlorophyll fluorescence ratio in phaseolus vulgaris and pisum sativum: the role of the photosystem I contribution to the $735 \mathrm{~nm}$ fluorescence band, Photochem. Photobiol., 72, 75-84, 2000.

Behrenfeld, M. J., Westberry, T. K., Boss, E. S., O’Malley, R. T., Siegel, D. A., Wiggert, J. D., Franz, B. A., McClain, C. R., Feldman, G. C., Doney, S. C., Moore, J. K., Dall'Olmo, G., Milligan, A. J., Lima, I., and Mahowald, N.: Satellite-detected fluorescence reveals global physiology of ocean phytoplankton, Biogeosciences, 6, 779-794, doi:10.5194/bg-6-779-2009, 2009.

Bracher, A., Vountas, M., Dinter, T., Burrows, J. P., Röttgers, R., and Peeken, I.: Quantitative observation of cyanobacteria and diatoms from space using PhytoDOAS on SCIAMACHY data, Biogeosciences, 6, 751-764, doi:10.5194/bg-6-751-2009, 2009.

Callies, C., Corpaccioli, E., Eisinger, M., Hahne, A., and Lefebvre, A.: GOME-2 - MetOp's Second-Generation Sensor for Operational Ozone Monitoring, available at: http: //esamultimedia.esa.int/docs/metop/GOME-2-102.pdf (last access: 13 April 2013), ESA Bull.-Eur. Space, 103, 28-36, 2000.

Campbell, P. K. E., Middleton, E. M., McMurtrey, J. E., Corp, L. A., and Chappelle, E. W.: Assessment of vegetation stress using reflectance or fluorescence measurements, J. Environ. Qual., 36, 832-845, 2007.

Campbell, P. K. E., Middleton, E. M., Corp, L. A., and Kim, M. S.: Contribution of chlorophyll fluorescence to the apparent vegetation reflectance, Sci. Total Environ., 404, 433-439, 2008.

Chance, K. and Kurucz, R. L.: An improved high-resolution solar reference spectrum for Earth's atmosphere measurements in the ultraviolet, visible, and near infrared, J. Quant. Spectrosc. Rad. Trans., 111, 1289-1295, 2010.

Cheng, Y.-B., Middleton, E. M., Zhang, Q., Huemmrich, K. F., Campbell, P. K., Cook, B. D., Kustas, W. P., and Daughtry, C. S.: Integrating solar induced fluorescence and the photochemical reflectance index for estimating gross primary production in a cornfield, Remote Sens., 5, 6857-6879, 2013.

Corp, L. A., McMurtrey, J. E., Middleton, E. M., Mulchi, C. L., Chappelle, E. W., and Daughtry, C. S. T.: Fluorescence sensing systems: in vivo detection of biophysical variations in field corn due to nitrogen supply, Remote Sens. Environ., 86, 470479, 2003. 
Corp, L. A., Middleton, E. M., McMurtrey, J. E., Campbell, P. K. E., and Butcher, L. M.: Fluorescence sensing techniques for vegetation assessment, Appl. Optics, 45, 1023-1033, 2006.

Corp, L.A., Middleton, E. M., Campbell, P. K. E., Huemmrich, K. F., Cheng, Y. B., and Daughtry, C. S. T.: Spectral indices to monitor nitrogen driven carbon uptake in field corn, J. Appl. Remote Sens., 4, 0435555, doi:10.1117/1.3518455, 2010.

Cogliati, S., Verhoef, W., Kraft, S., Sabater, N., Alonso, L., Vicent, J., Moreno, J., Drusch, M., and Colombo, R.: Retrieval of suninduced fluorescence using advanced spectral fitting methods, Rem. Sens. Environ., 169, 344-357, 2015.

Damm, A., Guanter, L., Paul-Limoges, E., van der Tol, C., Hueni, A., Buchmann, N., Eugster, W., Ammann, C., and Schaepman, M. E.: Far-red sun-induced chlorophyll fluorescence shows ecosystem-specific relationships to gross primary production: An assessment based on observational and modeling approaches, Rem. Sens. Environ., 166, 91-105, 2015.

Daumard, F., Champagne, S., Fournier, A., Goulas, Y., Ounis, A., Hanocq, J.-F., and Moya, I.: A field platform for continuous measurement of canopy fluorescence, IEEE Trans. Geosci. Remote., 48, 3358-3368, 2010.

Dikty, S., Richer, A., Weber, M., Noël, S., Bovensmann, H., Wittrock, F., and Burrows, J. P.: GOME-2 on MetOp-A support for analysis of GOME-2 in-orbit degradation and impacts on level 2 data products, Final Report, Univ. Bremen, available at: http: //www.iup.uni-bremen.de/doas/reports (last access: 1 November 2015), 2012.

DLR - Deutsches Zentrum fur Luftund Raumfahrt: SCIAMACHY Level 1b-1c processing The SciaL1c Command-line tool software user's manual, ENV-SUM-DLR-SCIA-0071, Issue 6.0, 2006.

Drusch, M., Moreno, J., del Bello, U., Franco, R., Goulas, Y., Huth, A., Kraft, S., Middleton, E., Miglietta, F., Mohammad, G., Nedbal, L., Rascher, U., Schüttemeyer, D., and Verhoef, W.: The Fluorescence EXplorer (FLEX) Mission Concept- ESA's Earth Explorer 8 (EE8), IEEE Trans. Geosci. Rem. Sens. (TGRS), in press, 2016.

ESA: Report for Mission Selection: FLEX, ESA SP-1330/2 (2 volume series), European Space Agency (ESA) Communications, 197pp., Ed. M. Drusch, R. Colombo, M. Rossini, D. Schüttemeyer, and R. Bianchi with contributions from the FLEX Mission Advisory Group (MAG), Noordwijk, the Netherlands, available at: http://esamultimedia.esa.int/docs/EarthObservation/ SP1330-2_FLEX.pdf, last access: 1 November 2015.

Fell, F. and Fischer, J.: Numerical simulation of the light field in the atmosphere-ocean system using the matrix-operator method, J. Quant. Spectrosc. Rad. Trans., 69, 351-388, 2001.

Fournier, A., Daumard, F., Champagne, S., Ounis, A., Goulas, Y., and Moya, I.: Effect of canopy structure on sun-induced chlorophyll fluorescence, ISPRS J. Photogramm., 68, 112-120, doi:10.1016/j.isprsjprs.2012.01.003, 2012.

Frankenberg, C., Butz, A., and Toon, G. C.: Disentangling chlorophyll fluorescence from atmospheric scattering effects in $\mathrm{O}_{2}$ A-band spectra of reflected sun-light, Geophys. Res. Lett., 38, L03801, doi:10.1029/2010GL045896, 2011a.

Frankenberg, C., Fisher, J. B., Worden, J., Badgley, G., Saatchi, S. S., Lee, J.-E., Toon, G. C., Butz, A., Jung, M., Kuze, A., and Yokota, T.: New global observations of the terrestrial carbon cycle from GOSAT: patterns of plant fluores- cence with gross primary productivity, Geophys. Res. Lett., 38, L17706, doi:10.1029/2011GL048738, 2011b.

Frankenberg, C., O’Dell, C., Guanter, L., and McDuffie, J.: Remote sensing of near-infrared chlorophyll fluorescence from space in scattering atmospheres: implications for its retrieval and interferences with atmospheric CO2 retrievals, Atmos. Meas. Tech., 5, 2081-2094, doi:10.5194/amt-5-2081-2012, 2012.

Frankenberg, C., O’Dell, C., Berry, J., Guanter, L., Joiner, J., Köhler, P., Pollack, R., and Taylor, T. E.: Prospects for chlorophyll fluorescence remote sensing from the Orbiting Carbon Observatory-2, Remote Sens. Environ., 147, 1-12, 2014.

Gitelson, A. A., Buschmann, C., and Lichtenthaler, H. K.: Leaf chlorophyll fluorescence corrected for re-absorption by means of absorption and reflectance measurements, J. Plant Phys., 152, 283-296, 1998.

Gower, J. F. R., and King, S.: Validation of chlorophyll fluorescence derived from MERIS on the west coast of Canada, Intl. J. Remote Sens., 28, 625-635, 2007.

Gower, J. F. R., and King, S.: Use of satellite images of chlorophyll fluorescence to monitor the spring bloom in coastal waters, Intl J. Rem. Sens., 33, 7469-7481, 2012.

Gower, J. F. R.: On the use of satellite-measured chlorophyll fluorescence for monitoring coastal waters, Intl. J. Rem. Sens., 37, 2077-2086, doi:10.1080/01431161.2015.1111542, 2015.

Guan, K., Pan, M., Li, H. Wolf, A., Wu, J., Medvigy, D., Caylor, K. K., Sheffield, J., Wood, E. F., Malhi, Y., Liang, M., Kimball, J. S., Saleska, S. R., Berry, J., Joiner, J., Lyapustin, A. I.: Photosynthetic seasonality of global tropical forests controlled by hydroclimate, Nature Geosci., 8, 284-289, doi:10.1038/ngeo2382, 2015a.

Guan, K., Berry, J., Zhang, Y., Joiner, J., Guanter, L., Badgley, G., Lobell, D. B., 2015: Improving the monitoring of crop productivity using spaceborne solar-induced fluorescence, Global Change Biol., 22, 716-726, doi:10.1111/gcb.13136, 2015b.

Guanter, L., Alonso, L., Gómez-Chova, L., Amorós-López, J., VilaFrancés, J., and Moreno, J.: Estimation of solar-induced vegetation fluorescence from space measurements, Geophys. Res. Lett., 34, L08401, doi:10.1029/2007GL029289, 2007.

Guanter, L., Alonso, L., Gómez-Chova, L., Meroni, M., Preusker, R., Fischer, J., and Moreno, J.: Developments for vegetation fluorescence retrieval from spaceborne highresolution spectrometry in the $\mathrm{O}_{2} \mathrm{~A}$ and $\mathrm{O}_{2}-\mathrm{B}$ absorption bands, J. Geophys. Res., 115, D19303, doi:10.1029/2009JD013716, 2010.

Guanter, L., Frankenberg, C., Dudhia, A., Lewis, P. E., GómezDans, J., Kuze, A., Suto, H., and Grainger, R. G.: Retrieval and global assessment of terrestrial chlorophyll fluorescence from GOSAT space measurements, Remote Sens. Environ., 121, 236251, 2012.

Guanter, L., Rossini, M., Colombo, R., Meroni, M., Frankenberg, C., Lee, J.-E., and Joiner, J.: Using field spectroscopy to assess the potential of statistical approaches for the retrieval of sun-induced chlorophyll fluorescence from space, Remote Sens. Environ., 133, 52-61, 2013.

Guanter, L., Zhang, Y., Yung, M., Joiner, J., Voigt, M., Berry, J. A., Frankenberg, C., Huete, A. R., Zarco-Tejada, P. Lee, J.-E., Moran, M. S., Ponce-Campos, G., Beer, C., Camps-Valls, G., Buchmann, N., Gianelle, D., Klumpp, K., Cescatti, A., Baker, J. M., Griffis, T. J.: Global and time-resolved monitoring of crop 
photosynthesis with chlorophyll fluorescence, Proc. Natl. Acad. Sci., 111, E1327-E1333, doi:10.1073/pnas.1320008111, 2014.

Guanter, L., Aben, I., Tol, P., Krijger, J. M., Hollstein, A., Köhler, P., Damm, A., Joiner, J., Frankenberg, C., and Landgraf, J.: Potential of the TROPOspheric Monitoring Instrument (TROPOMI) onboard the Sentinel-5 Precursor for the monitoring of terrestrial chlorophyll fluorescence, Atmos. Meas. Tech., 8, 1337-1352, doi:10.5194/amt-8-1337-2015, 2015.

Hu, C., Muller-Karger, F. E., Taylor, C., Carder, K. L., Kelble, C., Johns, E., and Heil, C. A.: Red tide detection and tracing using MODIS fluorescence data: A regional example in SW Florida coastal waters, Remote Sens. Environ., 97, 311-321, doi:10.1016/j.rse.2005.05.013, 2005.

Joiner, J., Yoshida, Y., Vasilkov, A. P., Yoshida, Y., Corp, L. A., and Middleton, E. M.: First observations of global and seasonal terrestrial chlorophyll fluorescence from space, Biogeosciences, 8, 637-651, doi:10.5194/bg-8-637-2011, 2011.

Joiner, J., Yoshida, Y., Vasilkov, A. P., Middleton, E. M., Campbell, P. K. E., Yoshida, Y., Kuze, A., and Corp, L. A.: Filling-in of near-infrared solar lines by terrestrial fluorescence and other geophysical effects: simulations and space-based observations from SCIAMACHY and GOSAT, Atmos. Meas. Tech., 5, 809-829, doi:10.5194/amt-5-809-2012, 2012.

Joiner, J., Guanter, L., Lindstrot, R., Voigt, M., Vasilkov, A. P., Middleton, E. M., Huemmrich, K. F., Yoshida, Y., and Frankenberg, C.: Global monitoring of terrestrial chlorophyll fluorescence from moderate-spectral-resolution near-infrared satellite measurements: methodology, simulations, and application to GOME-2, Atmos. Meas. Tech., 6, 2803-2823, doi:10.5194/amt-6-2803-2013, 2013 (data available at: http://avdc.gsfc.nasa.gov/index.php?site=1353468771\&id= 75\&go=list\&path=/MetOp-A/level3).

Joiner, J., Yoshida, Y., Vasilkov, A. P., Schaefer, K., Jung, M., Guanter, L., Zhang, Y., Garrity, S., Middleton, E. M., Huemmrich, K. F., Gu, L., Belelli Machesini, L.: The seasonal cycle of satellite chlorophyll observations and its relationship to vegetation phenology and ecosystem-atmosphere carbon exchange, Remote Sens. Environ., 152, 375-391, doi:10.1016/j.rse.2014.06.022, 2014.

Khosravi, N., Vountas, M., Rozanov, V. V., Bracher, A., Wolanin, A. and Burrows, J. P.: Retrieval of terrestrial plant fluorescence based on the in-filling of far-red Fraunhofer lines using SCIAMACHY observations. Front. Environ. Sci., 3, doi:10.3389/fenvs.2015.00078, 2015.

Koelemeijer, R. B. A., Stammes, P., Hovenier J. W., and de Haan, J. F.: A fast method for retrieval of cloud parameters using oxygen A band measurements from the Global Ozone Monitoring Experiment, J. Geophys. Res., 106, 3475-3490, 2001.

Köhler, P., Guanter, L., and Joiner, J.: A linear method for the retrieval of sun-induced chlorophyll fluorescence from GOME-2 and SCIAMACHY data, Atmos. Meas. Tech., 8, 2589-2608, doi:10.5194/amt-8-2589-2015, 2015.

Kokhanovsky, A. A., Rozanov, V. V., Zege, E. P., Bovensmann, H., and Burrows, J. P.: A semianalytical cloud retrieval algorithm using backscattered radiation in $0.4-2.4 \mu \mathrm{m}$ spectral region, J. Geophys. Res., 108, 4008, doi:10.1029/2001JD001543, 2003.

Kuze, A., and Chance, K. V.: Analysis of cloud top height and cloud coverage from satellites using the $\mathrm{O}_{2} \mathrm{~A}$ and $\mathrm{B}$ bands, J. Geophys. Res., 99, 14481-14491, 1994.
Lampel, J., Frieß, U., and Platt, U.: The impact of vibrational Raman scattering of air on DOAS measurements of atmospheric trace gases, Atmos. Meas. Tech., 8, 3767-3787, doi:10.5194/amt-8-3767-2015, 2015.

Lee, J.-E., Frankenberg, C., van der Tol, C., Berry, J. A., Guanter, L., Boyce, C. K., Fisher, J. B., Morrow, E., Worden, J. R., Asefi, S., Badgley, G., and Saatchi, S.: Amazonian productivity to seasonal water stress: observations from GOSAT chlorophyll fluorescence, Proc. Roy. Soc. B, 280, 20130171, doi:10.1098/rspb.2013.0171, 2013.

Lee, J.-E., Berry, J. A., van der Tol, C., Yang, X., Guanter, L., Damm, A., Baker, I., and Frankenberg, C.: Simulations of chlorophyll fluorescence incorporated into the Community Land Model version 4, Glob. Change Biol., 21, 3469-3477, doi:10.1111/gcb.12948, 2015.

Lewis, S. L., Brando, P. M., Phillips, O. L., van der Heijden, G. M. F., and Nepstad, D. C.: The 2010 Amazon Drought, Science, 331, 554-554, doi:10.1126/science.1200807, 2011.

Li, C., Joiner, J., Krotkov, N. A., and Bhartia, P. K.: A fast and sensitive new satellite $\mathrm{SO}_{2}$ retrieval algorithm based on principal component analysis: Application to the ozone monitoring instrument, Geophys. Res. Lett., 40, 1-5, doi:10.1002/2013GL058134, 2013.

Li, C., Joiner, J., Krotkov, N. A., and Dunlap, L.: A new method for global retrievals of $\mathrm{HCHO}$ total columns from the Suomi National Polar-orbiting Partnership Ozone Monitoring and Profiler Suite, Geophys. Res. Lett., 42, 2515-2522, doi:10.1002/2015GL063204, 2015.

Lichtenberg, G., Kleipool, Q., Krijger, J. M., van Soest, G., van Hees, R., Tilstra, L. G., Acarreta, J. R., Aben, I., Ahlers, B., Bovensmann, H., Chance, K., Gloudemans, A. M. S., Hoogeveen, R. W. M., Jongma, R. T. N., Noël, S., Piters, A., Schrijver, H., Schrijvers, C., Sioris, C. E., Skupin, J., Slijkhuis, S., Stammes, P., and Wuttke, M.: SCIAMACHY Level 1 data: calibration concept and in-flight calibration, Atmos. Chem. Phys., 6, 5347-5367, doi:10.5194/acp-6-5347-2006, 2006.

Lichtenthaler, H. K.: Chlorophyll fluorescence signatures of leaves during the autumnal chlorophyll breakdown, J. Plant Physiol. 131, 101-110, 1987.

Lichtenthaler, H. K.: Applications of chlorophyll fluorescence in photosynthesis research, stress physiology, hydrology and remote sensing, Kluwer Academic Publishers, P.O. Box 17, 3300, AA Dordrecht, the Nederlands, 1988.

Lichtenthaler, H. K.: Vegetation stress: an introduction to the stress concept in plants, J. Plant Physiol., 148, 4-14, 1996.

Lichtenthaler, H. K., and Schweiger, J.: Cell wall bound ferulic acid, the major substance of the blue-green fluorescence emission of plants, J. Plant Phys., 152, 272-282, doi:10.1016/S01761617(98)80142-9, 1998.

Loyola, D., Thomas, W., Livschitz, Y., Ruppert, T., Albert, P., and Hollmann, R.: Cloud properties derived from GOME/ERS-2 backscatter data for trace gas retrieval, IEEE Trans. Geosci. Remote Sens., 45, 2747-2758, 2007.

Lucht, W., Schaaf, C. B., and Strahler, A. H.: An Algorithm for the retrieval of albedo from space using semiempirical BRDF models, IEEE T. Geosci. Remote, 38, 977-998, 2000.

Mazzoni, M., Falorni, P., and Verhoef, W.: High-resolution methods for fluorescence retrieval from space, Opt. Express, 15, 15649$15663,2010$. 
Mazzoni, M., Meroni, M., Fortunato, C., Colombo, R., and Verhoef, W.: Retrieval of maize canopy fluorescence and reflectance by spectral fitting in the $\mathrm{O}_{2}-\mathrm{A}$ absorption band, Remote Sens. Environ., 124, 72-82, 2012.

McKibben, S. M., Strutton, P. G., Foley, D. G., Peterson, T. D., and White, A. E.: Satellite-based detection and monitoring of phytoplankton blooms along the Oregon coast, J. Geophys. Res., 117, C12002, doi:10.1029/2012JC008114, 2012.

Meroni, M., Rossini, M., Guanter, L., Alonso, L., Rascher, U., Colombo, R., and Moreno, J.: Remote sensing of solar-induced chlorophyll fluorescence: review of methods and applications, Remote Sens. Environ., 113, 2037-2051, 2009.

Middleton, E. M., Cheng, Y.-B., Campbell, P. E., Huemmrich, K. F., Corp, L. A., Bernardes, S., Zhang, Q., Landis, D. R., Kustas, W. P., Daughtry, C. S. T., Alfieri, J. G., and Russ, A. L.: Multi-angle hyperspectral observations using fluorescence and PRI to detect plant stress and productivity in a cornfield, EARSeL eProceedings, Special Issue 2, 2015: 9th EARSeL Imaging Spectroscopy Workshop, 2015, Luxembourg City, Luxembourg, 13 pp., 2015.

Morrison, J. R., and Goodwin, D. S.: Phytoplankton photocompensation from space-based fluorescence measurements, Geophys. Res. Lett., 37, L06603, doi:10.1029/2009GL041799, 2010.

Munro, R., Eisinger, M., Anderson, C., Callies, J., Corpaccioli, E., Lang, R., Lefebvre, A., Livschitz, Y., and Perez Albinana, A.: GOME-2 on MetOp: from In-Orbit Verification to Routine Operations, in: Proceedings of EUMETSAT Meteorological Satellite Conference, Helsinki, Finland, 12-16 June 2006.

O’Dell, C. W., Connor, B., Bösch, H., O’Brien, D., Frankenberg, C., Castano, R., Christi, M., Eldering, D., Fisher, B., Gunson, M., McDuffie, J., Miller, C. E., Natraj, V., Oyafuso, F., Polonsky, I., Smyth, M., Taylor, T., Toon, G. C., Wennberg, P. O., and Wunch, D.: The ACOS $\mathrm{CO}_{2}$ retrieval algorithm - Part 1: Description and validation against synthetic observations, Atmos. Meas. Tech., 5, 99-121, doi:10.5194/amt-5-99-2012, 2012.

O’Malley, R. T., Behrenfeld, M. J., Westberry, T. K., Milligan, A. J., Shang, S., Yan, J.: Geostationary satellite observations of dynamic phytoplankton photophysiology, Geophys. Res. Lett., 41, 5052-5059, doi:10.1002/2014GL060246, 2014.

Parazoo, N. C., Bowman, K., Frankenberg, C., Lee, J. E., Fisher, J. B., Worden, J., and Jones, D.: Interpreting seasonal changes in the carbon balance of southern Amazonia using measurements of $\mathrm{XCO}_{2}$ and chlorophyll fluorescence from GOSAT, Geophys. Res. Lett., 40, 2829-2833, 2013.

Parazoo N. C., Bowman K., Fisher J. B., Frankenberg C., Jones D. B., Cescatti A., Perez-Priego O., Wohlfahrt, G., and Montagnani, L.: Terrestrial gross primary production inferred from satellite fluorescence and vegetation models, Global Change Biol., 20, 3103-3121, doi:10.1111/gcb.12652, 2014.

Porcar-Castell, A., Tyystjärvi, E., Atherton, J., van der Tol, C., Flexas, J., Pfündel, E. E., Moreno, J., Frankenberg, C., and Berry, J. A.: Linking chlorophyll a fluorescence to photosynthesis remote sensing application: mechanisms and challenges, J. Exp. Botany, 65, 4065-4095, doi:10.1093/jxb/eru191, 2014.

Preusker, R., and Lindstrot, R.: Remote sensing of cloud-top pressure using moderately resolved measurements within the oxygen A band - a sensitivity study, J. Appl. Meteorol. Clim., 48, 15621574, 2009.

Rascher, U., Agati, G., Alonso, L., Cecchi, G., Champagne, S., Colombo, R., Damm, A., Daumard, F., de Miguel, E., Fernandez,
G., Franch, B., Franke, J., Gerbig, C., Gioli, B., Gómez, J. A., Goulas, Y., Guanter, L., Gutiérrez-de-la-Càmara, Ó., Hamdi, K., Hostert, P., Jiménez, M., Kosvancova, M., Lognoli, D., Meroni, M., Miglietta, F., Moersch, A., Moreno, J., Moya, I., Neininger, B., Okujeni, A., Ounis, A., Palombi, L., Raimondi, V., Schickling, A., Sobrino, J. A., Stellmes, M., Toci, G., Toscano, P., Udelhoven, T., van der Linden, S., and Zaldei, A.: CEFLES2: the remote sensing component to quantify photosynthetic efficiency from the leaf to the region by measuring sun-induced fluorescence in the oxygen absorption bands, Biogeosciences, 6, 11811198, doi:10.5194/bg-6-1181-2009, 2009.

Rascher, U., Alonso, L., Burkart, A., Cilia, C., Cogliati, S., Colombo, R., Damm, A., Drusch, M., Guanter, L., Hanus, J., Hyvärinen, T., Julitta, T., Jussila, J., Kataja, K., Kokkalis, P., Kraft, S., Kraska, T., Matveeva, M., Moreno, J., Muller, O., Panigada, C., Pikl, M., Pinto, F., Prey, L., Pude, R., Rossini, M., Schickling, A., Schurr, U., Schüttemeyer, D., Verrelst, J. and Zemek, F.: Sun-induced fluorescence - a new probe of photosynthesis: First maps from the imaging spectrometer HyPlant, Glob. Change Biol., 21, 4673-4684. doi:10.1111/gcb.13017, 2015.

Rinderle, U., and Lichtenthaler, H.: The chlorophyll fluorescence ratio F690/F735 as a possible stress indicator, in: Applications of Chlorophyll Fluorescene in Photosynthesis Research, Stress Physiology, edited by: Lichtenthaler, H., Hydrobiology and Remote Sensing, 189-196, Springer, the Netherlands, 1988.

Rodgers, C. D.: Characterization and error analysis of profiles retrieved from remote sounding measurements, J. Geophys. Res., 95, 5587-5595, 1990.

Rothman, L. S., Gordon, I. E., Barbe, A., Benner, D. C., Bernath, P. F., Birk, M., Boudon, V., Brown, L. R., Campargue, A., Champion, J., Chance, K., Coudert, L. H., Dana, V., Devi, V. M., Fally, S., Flaud, J. M., Gamache, R. R., Goldman, A., Jacquemart, D., Kleiner, I., Lacome, N., Lafferty, W. J., Mandin, J., Massie, S. T., Mikhailenko, S. N., Miller, C. E., Moazzen-Ahmadi, N., Naumenko, O. V., Nikitin, A. V., Orphal, J., Perevalov, V. I., Perrin, A., Predoi-Cross, A., Rinsland, C. P., Rotger, M., Simecková, M., Smith, M. A. H., Sung, K., Tashkun, S. A., Tennyson, J., Toth, R. A., Vandaele, A. C., and Vander Auwera, J.: The HITRAN 2008 molecular spectroscopic database, J. Quant. Spectrosc. Rad. Trans., 110, 533-572, 2009.

Rossini, M., Nedbal, L., Guanter, L., Ač, A., Alonso, L., Burkart, A., Cogliati, S., Colombo, R., Damm, A., Drusch, M., Hanus, J., Janoutova, R.,Julitta, T., Kokkalis, P., Moreno, J., Novotny, J., Panigada, C., Pinto, F., Schickling, A., Schüttemeyer, D., Zemek, F., and Rascher, U.: Red and far red Sun-induced chlorophyll fluorescence as a measure of plant photosynthesis, Geophys. Res. Lett., 42, 1632-1639, doi:10.1002/2014GL062943, 2015.

Sanders, A. F. J. and de Haan, J. F.: Retrieval of aerosol parameters from the oxygen A band in the presence of chlorophyll fluorescence, Atmos. Meas. Tech., 6, 2725-2740, doi:10.5194/amt-62725-2013, 2013.

Sanders, A. F. J., de Haan, J. F., Sneep, M., Apituley, A., Stammes, P., Vieitez, M. O., Tilstra, L. G., Tuinder, O. N. E., Koning, C. E., and Veefkind, J. P.: Evaluation of the operational Aerosol Layer Height retrieval algorithm for Sentinel-5 Precursor: application to $\mathrm{O}_{2}$ A band observations from GOME-2A, Atmos. Meas. Tech., 8, 4947-4977, doi:10.5194/amt-8-4947-2015, 2015. 
Subhash, N. and Mohanan, C. N.: Curve-fit analysis of chlorophyll fluorescence spectra: application to nutrient stress detection in sunflower, Remote Sens. Environ., 60, 347-356, 1997.

Sun, Y., Fu, R., Dickenson, R., Joiner, J., Frankenberg, C., Gu, L., Xia, Y., and Fernando, N.: Satellite solar-induced chlorophyll fluorescence reveals drought onset mechanisms: Insights from two contrasting extreme events, J. Geophys. Res., 120, 2427-2440, doi:10.1002/2015JG003150, 2015.

Tilstra, L. G., Tuinder, O. N. E., and Stammes, P.: A new method for in-flight degradation corrections of GOME-2 Earth reflectance measurements, with application to the absorbing aerosol index, Proc. 2012 EUMETSAT Meteorol. Sat. Conf., available at: http://www.temis.nl/airpollution/absaai (last access: 1 November 2015), 2012.

Vasilkov, A., Joiner, J., and Spurr, R.: Note on rotational-Raman scattering in the $\mathrm{O}_{2}$ A- and B-bands, Atmos. Meas. Tech., 6, 981-990, doi:10.5194/amt-6-981-2013, 2013.

Verrelst, J., Rivera, J. P., van der Tol, C., Magnani , F., Mohammed, G., Moreno, J.: Global sensitivity analysis of SCOPE v1.53 model: what drives canopy-leaving sun-induced fluorescence? Rem. Sens. Environ., 166, 8-21, 2015.

Walther, S., Voigt, M., Thum, T., Gonsamo, A., Zhang, Y., Köhler, P., Jung, M., Varlagin, A. and Guanter, L.:, Satellite chlorophyll fluorescence measurements reveal large-scale decoupling of photosynthesis and greenness dynamics in boreal evergreen forests, Glob. Change Biol., 22, 2979-2996, doi:10.1111/gcb.13200, 2015.

Wang, S., Huang, C., Zhang, L., Lin, Y., Cen, Y., Wu, T.: Monitoring and assessing the 2012 drought in the great plains: analyzing satellite-retrieved solar-induced chlorophyll fluorescence, drought indices, and gross primary production, Remote Sens., 61, doi:10.3390/rs8020061, 2016.

Westberry, T. K., Behrenfeld, M. J., Milligan, A. J., and Doney, S. C.: Retrospective satellite ocean color analysis of purposeful and natural ocean iron fertilization, Deep Sea Research Part I: Oceanographic Res. Pap., 73, 1-16, doi:10.1016/j.dsr.2012.11.010, 2013.

Wolanin, A., Rozanov, V. V., Dinter, T., Noël, S., Vountas, M., Burrows, J. P., and Bracher, A.: Global retrieval of marine and terrestrial chlorophyll fluorescence at its red peak using hyperspectral top of atmosphere radiance measurements: Feasibility study and first results, Remote Sens. Environ., 166, 243-261, doi:10.1016/j.rse.2015.05.018, 2015.
Yang, X., Tang, J., Mustard, J. F., Lee, J.-E., Rossini, M., Joiner, J., Munger, W., Kornfield, A., and Richardson, A. D.: Solar-induced chlorophyll fluorescence correlates with canopy photosynthesis on diurnal and seasonal scales in a temperature deciduous forest, Geophys. Res. Lett., 42, 2977-2987, doi:10.1002/2015GL063201, 2015.

Yoshida, Y., Joiner, J., Tucker, C., Berry, J., Lee, J.-E., Walker, G., Reichle, R., Koster, R., Lyapustin, A., and Wang, Y.: The 2010 Russian drought impact on satellite measurements of solar-induced chlorophyll fluorescence: Insights from modeling and comparisons with parameters derived from satellite reflectances, Remote Sens. Environ., 166, 163-177, doi:10.1016/j.rse.2015.06.008, 2015.

Zarco-Tejada, P. J., Miller, J. R., Mohammed, G. H., and Noland, T. L.: Chlorophyll fluorescence effects on vegetation apparent reflectance: I. Leaf-level measurements and model simulations, Remote Sens. Environ., 74, 582-595, 2000.

Zarco-Tejada, P. J., Pushnik, J. C., Dobrowski, S., Ustin, S. L.: Steady-state chlorophyll a fluorescence detection from canopy derivative reflectance and double-peak red-edge effects, Remote Sens. Environ., 84, 283-294, 2003.

Zhang, Y., Guanter, L., Berry, J. A., Joiner, J., van der Tol, C., Huete, A., Gitelson, A., Voigt, M., Köhler, P.: Estimation of vegetation photosynthetic capacity from space-based measurements of chlorophyll fluorescence for terrestrial biosphere models, Global Change Biol., 20, 3727-3742, doi:10.1111/gcb.12664, 2014.

Zoogman, P., Liu, X., Suleiman, R., M., Pennington, W. F., Flittner, D. E., Al-Saadi, J. A., Hilton, B. B., Nicks, D. K., Newchurch, M. J., Carr, J. L., Janz, S. J., Andraschko, M. R., Arola, A., Baker, B. D., Canova, B. P., Chan Miller, C., Cohen, R. C., Davis, J. E., Dussault, M. E., Edwards, D. P., Fishman, J., Ghulam, A., González Abad, G., Grutter, M., Herman, J. R., Houck, J., Jacob, D. J., Joiner, J., Kerridge, B. J., Kim, J., Krotkov, N. A., Lamsal, L., Li, C., Lindfors, A., Martin, R. V., McElroy, C. T., McLinden, C., Natraj, V., Neil, D. O., Nowlan, C. R., O’Sullivan, E. J., Palmer, P. I., Pierce, R. B., Pippin, M. R., Saiz-Lopez, A., Spurr, R. J. D., Szykman, J. J., Torres, O., Veefkind, J. P., Veihelmann, B., Wang, H., Wang, J., and Chance, K.: Tropospheric emissions: Monitoring of pollution (TEMPO), J. Quant. Spectrosc. Ra., doi:10.1016/j.jqsrt.2016.05.008, 2016. 